\title{
The impact of flavonoids on spatial memory in rodents: from behaviour to underlying hippocampal mechanisms
}

\author{
Catarina Rendeiro · Jeremy P. E. Spencer · \\ David Vauzour · Laurie T. Butler · Judi A. Ellis · \\ Claire M. Williams
}

Received: 23 July 2009/Accepted: 28 July 2009/Published online: 2 September 2009

(C) Springer-Verlag 2009

\begin{abstract}
Emerging evidence suggests that a group of dietary-derived phytochemicals known as flavonoids are able to induce improvements in memory, learning and cognition. Flavonoids have been shown to modulate critical neuronal signalling pathways involved in processes of memory, and therefore are likely to affect synaptic plasticity and long-term potentiation mechanisms, widely considered to provide a basis for memory. Animal dietary supplementation studies have further shown that flavonoidrich foods are able to reverse age-related spatial memory and spatial learning impairments. A more accurate understanding of how a particular spatial memory task works and of which aspects of memory and learning can be assessed in each case, are necessary for a correct interpretation of data relating to diet-cognition experiments. Further understanding of how specific behavioural tasks relate to the functioning of hippocampal circuitry during learning processes might be also elucidative of the specific observed memory improvements. The overall goal of this review is to give an overview of how the hippocampal circuitry operates as a memory system during behavioural tasks, which we believe will provide a new insight into the underlying mechanisms of the action of flavonoids on cognition.
\end{abstract}

Keywords Spatial $\cdot$ Memory $\cdot$ Learning $\cdot$ Hippocampus . Flavonoids

C. Rendeiro · L. T. Butler · J. A. Ellis · C. M. Williams ( $₫)$ School of Psychology and Clinical Language Sciences, University of Reading, Reading RG6 6AP, UK

e-mail: claire.williams@reading.ac.uk

C. Rendeiro - J. P. E. Spencer - D. Vauzour

Molecular Nutrition Group, School of Chemistry, Food and Pharmacy, University of Reading, Reading RG6 6AP, UK

\section{Introduction}

There has been intense interest in the potential of flavonoids to modulate neuronal function and prevent agerelated neurodegeneration. The use of flavonoid-rich plant or food extracts in humans and animal dietary supplementation studies have indicated that they are capable of inducing improvements in cognitive function by protecting vulnerable neurons, enhancing existing neuronal function or by stimulating neuronal regeneration $[125,193,194$, 216]. Many of these studies have been conducted in rodent models which have been used as models of human declarative memory (Fig. 1) to predict the potential effects of flavonoids on human cognitive performance [34, 37, 38, 44, 102, 112, 119, 120, 162, 189, 194, 224]. Declarative memory in humans represents objects, places and events in the external world and acts to form associations between them. This representation is flexible, as it can be stored and subsequently expressed in novel situations. Similarly, rodents acquire declarative memories when they 'learn' the required route within a specific maze environment, indicating that they have acquired a flexible representation of space in order to guide their behaviour in specific situations [198]. A particular aspect of declarative memory that has been used to model the effects of diet on behaviour is spatial memory. Spatial memory is well characterised in both rodents and humans and it is dependent on the hippocampus in both species [151]. Additionally, spatial memory is severely affected by age in both species and as such constitutes an excellent model in which to evaluate the potential of flavonoids to reverse age cognitive deficits.

However, the potential effects of diet on memory and learning are likely to be relatively subtle. Therefore, the demonstration of a clear 'cause and effect' relationship between consumption of a particular flavonoid-rich food and 
Fig. 1 Localization of spatial memory in the human memory system. Declarative and nondeclarative memory are the two main types of human memory; declarative memory is dependent on the medial temporal lobe and hippocampus and its retrieval requires conscious attention, whilst nondeclarative memory is related with amygdala, cerebellum, striatum and reflex pathways and can be retrieved effortlessly (does not require conscious attention). Spatial memory is a type of declarative memory that has been extensively studied in rodents and is dependent on hippocampus in both humans and rodents. Short-term memories are consolidated into long-term memories by repetition (based on [198, 200])

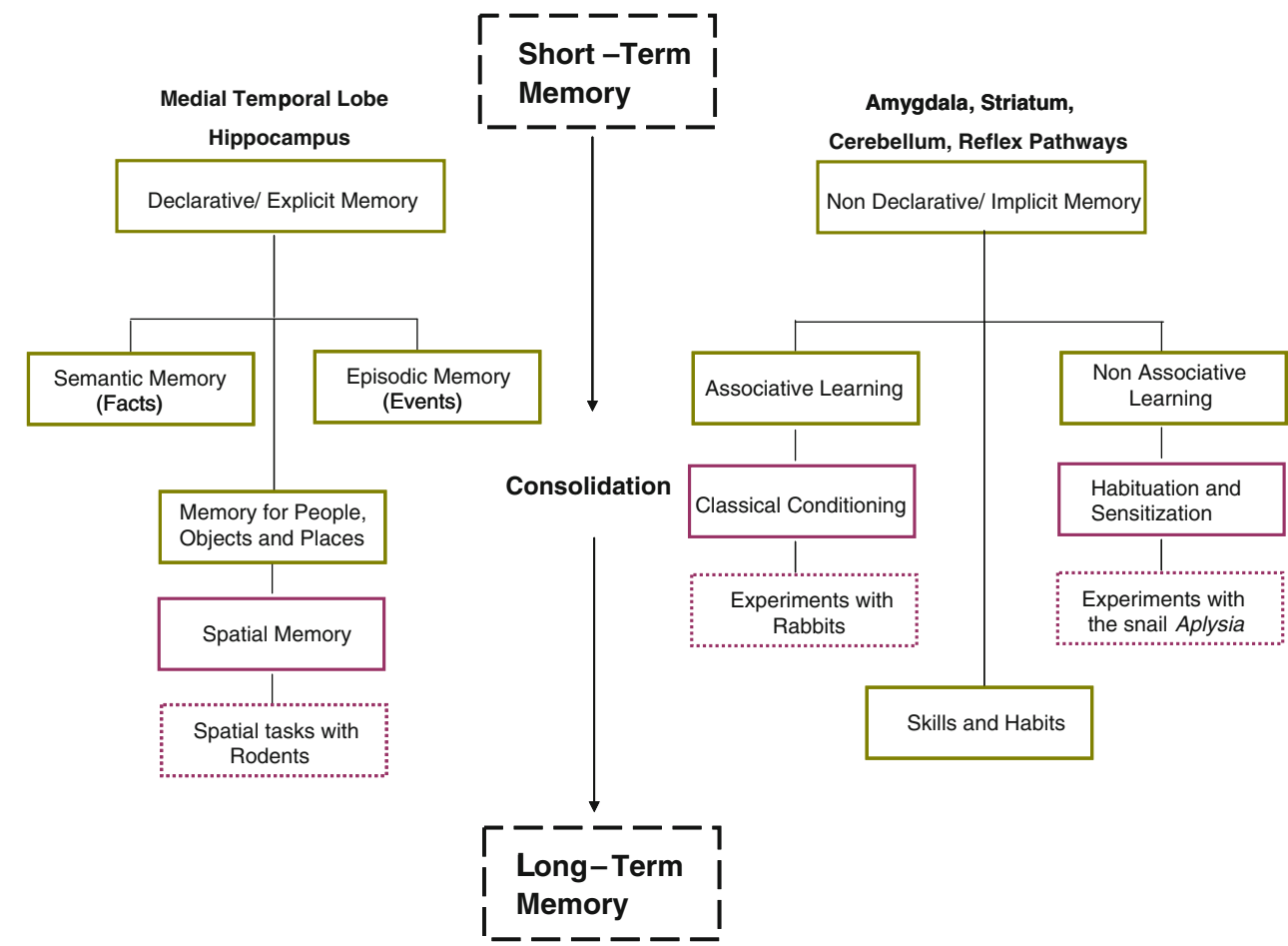

environment and can remember complex relationships between visuospatial cues in similar ways to humans. As such, several maze environments, most notably the Radial Arm Maze [154] and Morris Water Maze [136], have been developed to assess rodent spatial memory and learning. It has been comprehensively reported that rats show distinct age-related deficits in such spatial learning tasks [14] and there is direct evidence that spatial memory tasks are sensitive to hippocampal injury [82]. Indeed, the performance of aged rats in T-maze, eight-arm radial maze and Morris water maze tasks suggests that aged rats have impaired spatial learning but are not impaired in non-spatial versions of the tasks. This indicates that spatial learning appears to be particularly vulnerable to the effects of ageing [15, 17, 137], whilst the ability to solve even difficult non-spatial tasks is unaffected by age. Typically, in maze learning, the animal is required to move from a start position to a goal location by learning the spatial layout of the maze, although this may be motivated either by a food reward or an aversive stimulus [57]. In the next section we will compare the two major behavioural apparatuses used to assess spatial learning in rodents (Morris water maze and radial arm maze), in order to highlight the procedural and conceptual differences between them when measuring aspects of learning and memory.

\section{Radial arm maze}

The original version of the eight-radial arm maze task (RAM), also known as the 'Olton Task', was introduced by 
Olton and Samuelson in 1976 [154]. In the classic version of the task, each arm of the maze contains a food reward and the rat is required to visit each arm once only within a trial to locate all eight food rewards. Therefore, the task requires the animal to keep track of the already visited arms by making use of visuospatial cues located in the environment, thereby allowing it to collect the maximum number of food rewards. During each testing session, performance is evaluated by recording the number of times that the rat re-enters a previously visited arm with the number of re-entries recorded as 'short-term working memory errors'. This measure constitutes a measure of short-term working memory which is typically defined as the information that the rat should retain within each testing trial (in this case which arms it already visited). Learning in this task is usually inferred from the day-to-day improvements in task performance with rats typically making an increasing number of correct choices over the course of 1 or 2 weeks.

Several interesting versions of this task have been subsequently developed, including most notably the 'delayed non-matching to sample' (DNMS) and 'delayed matching to sample' (DMS) versions, in which an interval is imposed between the first four choices and the last four [3, 203] (Table 1). In both tasks, each trial has a 'sample phase' where the rats are allowed to collect food rewards from four arms (previously defined by the researcher), whilst the other four arms are blocked, and following a set interval (5 min$24 \mathrm{~h}$ ), a 'choice phase' during which the rat is returned to the maze and required to locate the remaining four food rewards (with all eight arms available). In the case of DNMS, four rewards are placed in the complementary four arms, so the rat is required to remember which arms were visited during the sample phase in order to locate the remaining four during the choice phase. In the DMS, following the sample phase, the four additional food rewards are placed in the same arms as during the sample phase. In both cases, the interval between sample and choice phases can be adjusted to test either short-term memory or longterm memory [57]. Quantification is achieved by recording the number of times that rats fail to enter the correct arms (i.e. containing a food reward) during the choice phase, and is denoted either a short-term or long-term memory error.

A popular version of the RAM task allows for distinguishing between short-term working memory and longterm reference memory in the same experiment. In this version, the same four arms are baited across repeated trials and the rat is expected to avoid the "never-baited arms" [98]. Correct performance here requires the long-term storage of the information across the days/trials and constitutes a measure of 'reference memory', with reference memory errors recorded as the number of entries into those arms never baited during experiments. Working memory can still be accessed here by recording re-entries into visited arms in the same trial. Other variations of the RAM task includes the simpler T-maze, Y-maze or X-maze tasks. These work by the same principle, but in this case the animals are presented with just two arm-choices, and are required to alternate between the two in order to obtain food rewards. Several versions of these tasks have been used (Table 1), since continuous alternation between the two arms to matching or non-matching versions in which an interval is imposed between sample phase and choice phase, similarly to what was described above for the RAM [49].

\section{Morris water maze}

The Morris Water Maze (MWM) was described almost 30 years ago, by Richard Morris, as a device to investigate spatial learning and memory in rodents and meanwhile it has become one of the most frequently used laboratory tools in behavioural science [136, 137]. Although, the MWM was designed to evaluate similar aspects of memory and learning as for the RAM, it does so via a different manner. The maze consists of a large circular pool filled with opaque water in which a small escape platform is hidden [136]. During a number of training trials, rats are required to learn the location of the hidden platform relying purely on the allocentric visuospatial cues available in the testing room [136]. During the acquisition stage of the task, the rat is placed in the pool in various starting positions, and the time taken to reach the platform (escape latency) as well as length of the path taken to the platform is recorded and constitutes a measure of task learning. Typically, the rats are given three consecutive days of training (6 trials/ day with 15 to 20-min intervals in between trials). Following the acquisition of the task, "probe trials" or "reversal learning tasks" can be performed to evaluate the retention of the learnt task and flexibility of re-learning, correspondingly. Probe trials are performed directly after the acquisition stage of the task (e.g. 24 h) or after several days to weeks to assess short-term and long-term memory, respectively $[41,222]$. In the probe trial task, the platform is removed and the rat is allowed to swim freely for a certain amount of time. Memory retention is quantified by measurement of the time that the animal spends in the quadrant where the platform used to be during the acquisition stage.

The 'reversal learning' task in MWM can be performed in addition to the classic task [41, 222]. Here, the position of the platform is changed and escape latency is measured during additional trials conducted within the same day. The reversal learning task evaluates the flexibility to relearn a new spatial location and to switch strategy. It can be repeated on a daily basis, switching the platform location every day. Typically, a series of trials are performed each 
Table 1 Summary of mazes and tasks used to evaluate spatial memory in rodents. For each maze (8-Radial Arm Maze; Morris Water Maze; Radial Arm Water Maze; T/Y-Maze) the different memory tasks that can be performed and the correspondent types of memory that are being assessed, as well as the parameters that should be recorded in each case $(\mathrm{ST}=$ Short-term; LT $=$ Long-term; $\mathrm{WME}=$ Working memory errors; $\mathrm{RME}=$ Reference memory errors) are presented

\begin{tabular}{|c|c|c|c|c|}
\hline Maze & Task/paradigm & $\begin{array}{l}\text { Memory assessed } \\
\text { (short/long term) }\end{array}$ & Recorded parameters & Reference \\
\hline \multirow[t]{4}{*}{$\begin{array}{l}\text { Eight-arm radial } \\
\text { maze }\end{array}$} & Olton Task & ST working memory & $\begin{array}{l}\text { Number of re-entries in arms in the first } 8 \\
\text { choices (WME); Total choices required } \\
\text { to visit all } 8 \text { arms: Time taken to } \\
\text { complete the trial }\end{array}$ & {$[154]$} \\
\hline & $\begin{array}{l}\text { Delayed non-matching } \\
\text { to sample }\end{array}$ & ST working memory & $\begin{array}{l}\text { Entries into the rewarded arms in the } \\
\text { sample phase and Re-entries into arms } \\
\text { previously visited within the choice } \\
\text { phase (WME) }\end{array}$ & [139] \\
\hline & $\begin{array}{l}\text { Working and reference } \\
\text { memory task }\end{array}$ & $\begin{array}{l}\text { ST working memory and LT } \\
\text { reference memory }\end{array}$ & $\begin{array}{l}\text { Number of entries in arms that were never } \\
\text { baited (RME); Number of re-entries into } \\
\text { arms within a trial (WME) }\end{array}$ & {$[98]$} \\
\hline & $\begin{array}{l}\text { Delayed matching to } \\
\text { sample }\end{array}$ & ST working memory & $\begin{array}{l}\text { Entries into no rewarded arms and Re- } \\
\text { entries into arms previously visited } \\
\text { within the choice phase (WME) }\end{array}$ & {$[53]$} \\
\hline \multirow[t]{3}{*}{ Morris water maze } & Classic task & Acquisition & Escape Latency compared across days & {$[136]$} \\
\hline & Spatial probe trial & ST or LT memory & $\begin{array}{l}\text { Time that the rat spent in the quadrant } \\
\text { that previously contained the platform }\end{array}$ & {$[136]$} \\
\hline & $\begin{array}{l}\text { Reversal learning } \\
\text { paradigm }\end{array}$ & $\begin{array}{l}\text { Learning flexibility/capacity and } \\
\text { ST working memory }\end{array}$ & $\begin{array}{l}\text { Escape latency, swim speed, distance } \\
\text { travelled, quadrant spent time- } \\
\text { comparison between trials in each day. }\end{array}$ & {$[10]$} \\
\hline \multirow[t]{3}{*}{$\begin{array}{l}\text { Radial arm water } \\
\text { maze }\end{array}$} & $\begin{array}{l}\text { Working and reference } \\
\text { memory task }\end{array}$ & $\begin{array}{l}\text { ST working memory and LT } \\
\text { reference memory }\end{array}$ & $\begin{array}{l}\text { Latency to find platform, Swim speed, } \\
\text { Distance travelled, WME (re-entries } \\
\text { within a trial) and RME (entries in arms } \\
\text { that do not contain the platform) }\end{array}$ & [189] \\
\hline & $\begin{array}{l}\text { Reversal learning } \\
\text { paradigm }\end{array}$ & $\begin{array}{l}\text { Learning flexibility and ST } \\
\text { working memory }\end{array}$ & $\begin{array}{l}\text { Latency to find platform, swim speed, } \\
\text { Distance travelled, working memory } \\
\text { errors (re-entries within a trial)- } \\
\text { comparison between trials in each day }\end{array}$ & [189] \\
\hline & "Continuous paradigm" & ST working memory & $\begin{array}{l}\text { Number of errors in the first } 8 \text { choices } \\
\text { (WME), total choices required to visit } \\
\text { all eight channels, time taken to } \\
\text { complete the trial }\end{array}$ & {$[142]$} \\
\hline \multirow[t]{3}{*}{$\mathrm{T} / \mathrm{Y}-\mathrm{maze}$} & $\begin{array}{l}\text { Continuous alternation } \\
\text { task }\end{array}$ & ST working memory & $\begin{array}{l}\text { Failure to alternate between the two arms } \\
\text { during a fixed period of time (WME) }\end{array}$ & [46] \\
\hline & $\begin{array}{l}\text { Delayed non-matching } \\
\text { to sample }\end{array}$ & ST working memory & $\begin{array}{l}\text { Number of times the animal fails to } \\
\text { alternate from sample phase to choice } \\
\text { phase (WME) }\end{array}$ & {$[2,12]$} \\
\hline & $\begin{array}{l}\text { Delayed matching to } \\
\text { sample }\end{array}$ & ST working memory & $\begin{array}{l}\text { Number of times the animal fails to } \\
\text { choose the arm that has been always } \\
\text { rewarded (WME) }\end{array}$ & {$[23,210]$} \\
\hline
\end{tabular}

day to evaluate how escape latency changes across trials within each day. In both cases, the standard working memory measures are typically escape latency and length of the swimming path (for a review see [41]) (Table 1).

\section{Comparison between the Radial Arm Maze and Morris Water Maze}

Although both of these maze environments are commonly used to assess spatial memory, they differ in a number of fundamental ways which impact on the way the rats utilise cognitive functions to solve the tasks. For example, can the outcomes of each task be related to each other and, more fundamentally, are animals accessing the same cognitive pathways during task resolution in the RAM and MWM task environments? In fact, contradictory findings have been reported in MWM and RAM tasks, with cognitive deficits in ischaemic rats observed during water maze tasks, but not in radial arm maze tasks [146]. Furthermore, rats with hippocampal CA1 cell loss (following global 
ischaemia) were found to have impaired performance in MWM tasks [147], but showed no impairment in working and reference memory in RAM tasks [98]. Hence, there is some indication that performance in the two maze environments may not necessarily be intimately correlated (see [89] for a review). The reasons for this relate to the fact that the two differ in many important aspects, in particular task complexity, experimental design, procedural variables (e.g. motivation, nature of walking, speed of learning), and confounding factors that may affect spatial learning (e.g. stress and anxiety, alternative strategies) $[73,78,180]$ (Table 2). First, the direct measures of working memory are rather different in both tasks. In the MWM the assessment is inferred from the animal's free search for the platform, whilst in the RAM that search is restricted in that once an arm is chosen the animal is not allowed to go back (or an error is immediate recorded). Thus, in the RAM a decision or choice can be made prior to reward, whilst in MWM there is only one outcome, the animals have to find the exact localization of the platform [89]. As such, the working memory measures in MWM appear more demanding and more likely to be affected by confounding factors, most notably motor skill performance [89, 223]. Several authors have argued that latency and path length do not necessarily measure search accuracy and, therefore, spatial learning and have suggested alternative measures for spatial learning in the MWM, such as the "average distance" to platform [65], path directionality [202] or cumulative distance to platform [42].

There are several studies which suggest that during performance of spatial memory paradigms, animals are likely to use associative mechanisms in addition to allocentric visuospatial information to solve the tasks [26, 27, 91, 99, 150, 153]. For example, in both MWM and RAM, deficits in hippocampal activity impair place learning, but not associative learning [51, 99]. Consequently, rats showing impaired use of visuospatial cues may solve the task by alternative associative processes, involving associations with local cues, such as odours, for example [209]. However, a difference has emerged between the MWM and RAM tasks regarding the use of alternative strategies with some evidence suggesting that RAM allows more chance for the adoption of alternative strategies for spatial navigation [89, 90, 93]. This is because the RAM task involves a choice between discrete arms which make it more likely that the rat will associate each arm with local cues, like odour trails or textures, which is not possible in MWM [89] (Table 2). A solution to this problem has been developed in the form of a Water Radial Arm Maze in which the radial arm configuration is maintained within an aqueous environment. Here, rats are required to swim to the platform in each arm and following the platform collapse are required search for alternative platforms in the other arms. Similar to the Olton Task version in the RAM, the number of platforms found in the end of the arms in the "wet" version would correspond to the number of rewards (correct choices) found in the RAM. The task has the advantage of keeping the discrete choices of the RAM, and at the same time avoids potential odour cues and discourages local associations. The results suggest that the wet version of RAM reinforces the use of allocentric spatial information compared to the classic RAM, in which it may be possible to use alternative strategies [142].

The use of alternative information, in parallel with visuospatial information, is also seen when observing regular searching patterns. In MWM tasks, automated tracking video systems have been used to provide a much simpler and effective way of detecting and even quantifying searching patterns, although in RAM tasks the detection of searching strategies is not so straightforward [89]. However, there are standard search strategies that have been identified in RAM tasks, such as those where the animal enters adjacent arms consecutively [48, 56, 152]. Despite
Table 2 Comparison between Morris Water Maze and Radial Arm Maze [41, 56, 73, 89, 181]

\begin{tabular}{|c|c|c|}
\hline Factors & MWM & RAM \\
\hline Spatial memory assessed & Short-term working memory & $\begin{array}{l}\text { Short-term working and } \\
\text { long-term reference } \\
\text { memory }\end{array}$ \\
\hline Speed of learning & Rapid & Slow \\
\hline Motivation & Aversive & Appetitive \\
\hline Type of search & Free & Constrained \\
\hline Nature of locomotion & Swimming & Walking \\
\hline Anxiety/stress levels & High levels & Low levels \\
\hline Search strategies & Easier to detect & Harder to detect \\
\hline Olfactory Information & Absent & More likely to be present \\
\hline $\begin{array}{l}\text { Likelihood of using additional } \\
\text { mechanisms (other than spatial) } \\
\text { to solve the task }\end{array}$ & Less likely & More likely \\
\hline
\end{tabular}


this, research has revealed that rats can and do follow different algorithm response patterns which are not easily detectable to solve maze tasks, thereby potentially masking poor performance [56].

Clearly, one way in which the MWM and RAM tasks differ is in their motivation to complete the task. Whilst the MWM task is an aversive task, in which rats are required to swim to a hidden platform in order to avoid drowning, the RAM task is motivated by food reward (Table 2). The mechanisms underlying the motivation to perform are distinct enough to potentially affect experimental factors like speed of learning and the strategy adopted by the animals. In MWM tasks, the learning process tends to be faster relative to RAM tasks, where the failure to find the reward is not life threatening. The slower learning process in RAM tasks is one reason why animals are more likely to use alternative strategies (other than spatial) to solve tasks. However, as Hodges [89] argues, the role of motivation in spatial learning is not clear, as working memory tasks in different food reward mazes (i.e. RAM and 3-door runway) result in different performances in hippocampal lesioned animals [61, 92, 98]. Nevertheless, stress is likely to be a key confounding factor in cognitive performance in spatial memory tasks. It is well reported that MWM tasks induce levels of stress higher than those experienced by the animals performing RAM tasks and that cognitive function is known to be affected by stress in rodents as it is in humans $[45,96]$. In particular, increased or decreased levels of adrenal stress hormones impair acquisition and retrieval of spatial information [178]. In fact, the aversive character of the MWM task has been identified by several authors as one of the mains disadvantages of the test $[22,41,202$, 222].

As discussed, the MWM and RAM tasks differ in speed of learning and consequently have different ranges of application [66]. This is an important factor when selecting a task to assess effects of diet. Whilst the MWM task tests for rapid acquisition of a spatial layout, RAM task learning is acquired over a longer period of time. Accordingly, in order to detect differences between groups in acute interventions the MWM is often described as more appropriate [89], whilst RAM tasks is perhaps more appropriate to investigate the effects of a chronic dietary intervention. However, it remains crucial to consider aspects of both tasks and feeding strategies as administration of a diet before and/or during the learning phase can have different cognitive outputs and may provide further information regarding potential interactions of the diet with the progress of learning. Finally, as researchers are typically looking for a 'gain of function' in the behavioural paradigm, the difficulty level of each task must be such as to make it possible to detect an incremental improvement in performance compared to the control animals. As such, behavioural task design and training regimes are also critical parameters to create the ideal test conditions to investigate the effects of diet [66].

Rodent models of ageing have been extensively used to investigate the potential beneficial actions of flavonoid-rich foods in reversing age-related cognitive impairments [34, 102, 162, 189, 219, 227]. The assessment of cognitive abilities in aged animals involves some measurement and methodological issues that become particularly critical when one attempts to relate changes at a cognitive level with neurobiological changes $[20,167]$. The reliability of behavioural scores is dependent on the certainty that the score reflects the cognitive ability of interest. For example, in the MWM, swim times may include a component of motor ability, which means that if the rats have a motor impairment, they may perform poorly in the task for reasons not directly related to spatial learning impairment. It is possible to use other measures of cognitive performance in MWM that are less influenced by possible motor impairments [65]. Additionally, visually cued water maze task (a visible flag placed in the platform) is commonly included as a control. If the rats perform normally when the location of the platform is apparent, so any deficit in locating the hidden platform (that it should be based on the relationships between external cues) cannot be attributed to motor impairments or visual impairments [167].

In non-aversive spatial paradigms, such as RAM, one of the critical methodological issues is related to aged rodents' motivation to perform. It is common to restrict the consumption of food to motivate aged animals to look for the treats in the maze [221]. However, in the case of dietary interventions this may be a problem, especially because food restriction is reported to enhance spatial memory in aged rodents $[72,166]$.

The operation of hippocampal circuitry as a memory system

There is a broad consensus that the hippocampus is intimately involved in learning and memory processes in both animals and humans. However, the extent of its involvement, as well as how hippocampal circuitry mediates memory processing is still a source of debate. Memory is an extremely complex process, as it involves the understanding of how different types of information are represented in the brain, how that information is processed and its distribution across a variety of neural systems. Since the cognitive mapping theory of O'Keefe and Nadel [151], several distinct experiment-driven theories of hippocampal function have been formulated using data from both animals and humans (Declarative theory [196, 199]; Multiple Trace-theory [138]; Dual-Process Theory [1, 145]; Relational Theory $[39,50])$. The main differences, which 
remain the subject of much discussion, are related to the nature of the memory representation, the duration of the memory (i.e. short, versus intermediate, versus long-term) and some of the memory processing mechanisms such as pattern separation, pattern association, and pattern completion.

Classic approaches using lesions and pharmacology and, more recently, targeted genetic techniques combined with in vivo physiology have shed light on the mechanisms and hippocampal circuits responsible for spatial memory [140, $141,175]$. In particular, the combination of behavioural and electrophysiological data has begun to address the different contribution of individual hippocampal subregions to spatial memory. Despite the different theories regarding hippocampal function, there is agreement that a memory is represented by the firing rates of a population of neurons and stored by synaptic modification, allowing later recall of that memory. When a rat explores a novel space, hippocampal 'place' cells, which encode a sense of location and not just simply reflect sensory input from the surrounding environment [149], express a firing pattern that is unique to that environment [132, 148]. Place-specific firing in the hippocampus is thought to reflect the integration of convergent input from grid cells of the entorhinal cortex (EC) where the firing locations originate a regular grid-like pattern that covers the environment that is being explored by the animal at that moment [83]. However, it is not clearly understood how the spatial information is converted from grid cells in the entorhinal cortex to place cells in the hippocampus.

Both primate and rodent hippocampus receive their main inputs via the EC, through the parahippocampal cortex (represented by the dorsal postrhinal cortex in the rats), and the perirhinal cortex from the processing streams of the neocortex, such as the temporal lobe, the frontal cortex and the parietal cortex (Reviewed in [106]) (Fig. 2a). In particular, the perirhinal cortex is thought to feed object information into the hippocampus for objectplace associations, as it is known to be implicated in paired associate learning and recognition memory $[124,133,134$, 233, 235] The parahippocampal cortex (Postrhinal cortex in rats) has been found to hold cells with spatial information in both macaques and rodents, indicating a potential involvement in the introduction of spatial information into the hippocampus [86, 176]. The connections that the hippocampus establishes are potentially able to bring together both object and spatial information to form an object-inplace representation, suggested to be the rat analogue of the general event-context/item representation that underlies episodic memory in humans [43, 144, 205]. In both species, rodent and primate, there is an input from the neocortex that includes not just visual, but auditory, somatosensory and olfactory information (Fig. 2a).
However, the topography and the relative contribution of this input differs across species [33]. In rodents, the perirhinal cortex receives mainly somatosensory, auditory and olfactory input, and the postrhinal cortex receives primarily visual input. In monkeys, both perirhinal and parahippocampal cortices receive extensive visual input and somatosensory information, whilst auditory information is directed mainly through the parahippocampal cortex. Furthermore, the relative amount of visual information processed in a rodent is considerably less than in a primate ( $42 \%$ of the neocortex in monkeys is dedicated to visual processing, compared to just $17.9 \%$ in rats). To the contrary the somatosensory and olfactory input is greater in rats compared with primates [33]. The additional input from amygdala and the obitofrontal cortex could provide information regarding stimulus-reward associations that are important in behavioural tasks that rely on treats to motivate animal performance as in the RAM tasks [187, 233, 234].

\section{The entorhinal cortex and grid cells}

The medial and lateral entorhinal cortices (MEC and LEC) receive input from postrhinal and perirhinal cortices, respectively. These two processing streams are relatively separated, carrying different types of information to the hippocampus (Fig. 2a) [33]; [32, 229]. The recent discovery of grid cells in the EC, which are able to fire in a precise, triangular grid pattern in a specific environment, is of inestimable importance in understanding the nature of the firing pattern that provides the major input to the hippocampus [83]. The grid cells are suggested to be a part of a system that keeps track of the rat's location by integrating direction and speed of movement, so there is a continuous update of the rat's position in a particular environment [62]. Additionally, entorhinal cells are reported to have the so-called "path equivalence" [58], meaning that EC cells fire in a similar pattern when the trajectory of the animal is spatially identical, independent of the specific context involved. Therefore, the EC is thought to be responsible for generalising similar trajectories across environments [58].

\section{Dentate gyrus—role in spatial pattern separation}

When the animal navigates a spatial environment, the dentate gyrus (DG) granule cells receive as an input, the activity of the entorhinal grid (EC) cells via the Perforant Pathway (Fig. 2b). It has been suggested that the DG acts as a competitive learning network to remove redundancy from the inputs (conjunction of sensory inputs as vestibular, olfactory, visual, auditory and somatosensory) generating a more orthogonal, sparse and categorised set of outputs for use in CA3 [168, 169, 173]. Whilst, EC neurons 

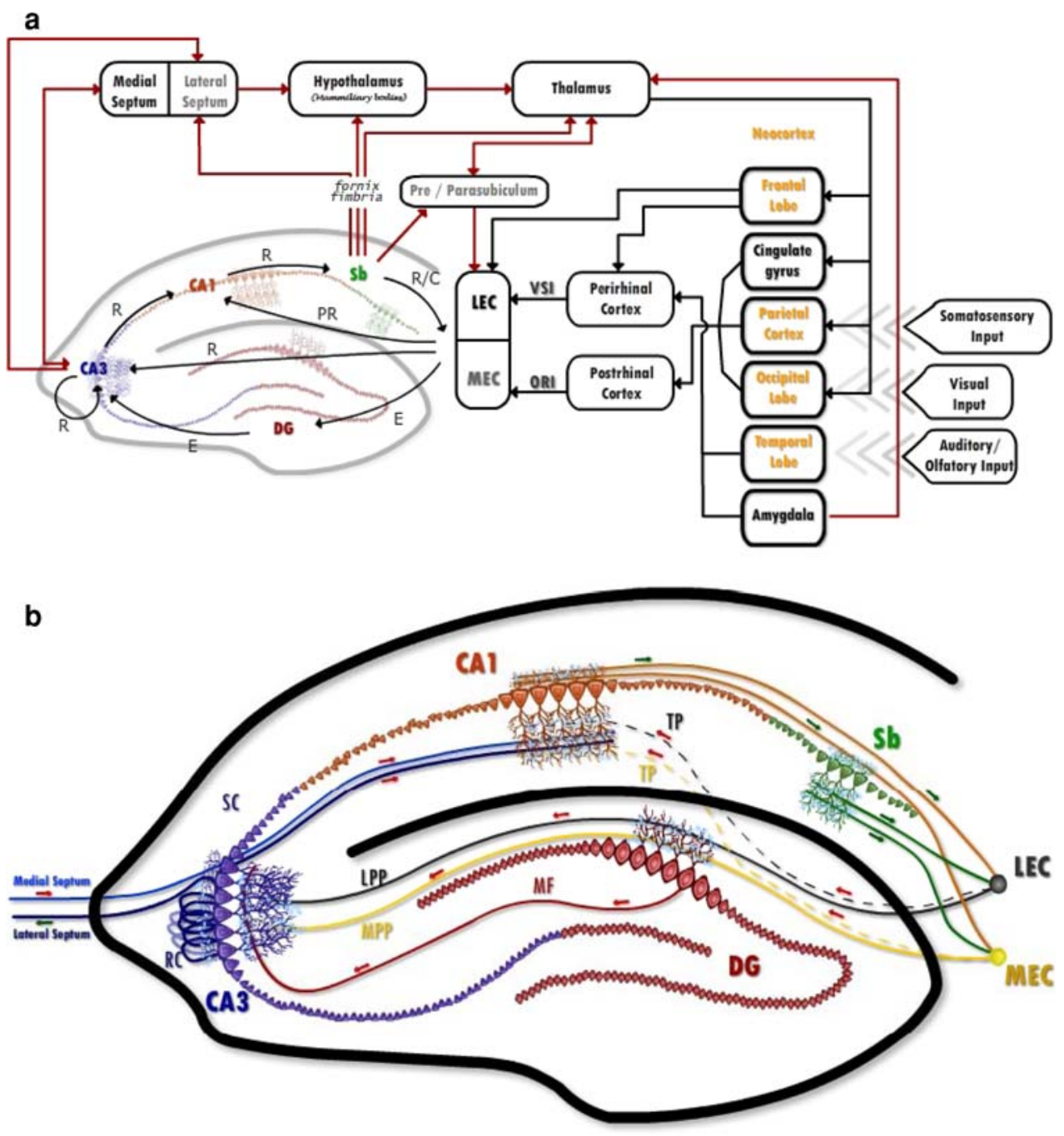

Fig. 2 The hippocampus and its connections. (a) The hippocampus lies in the medial temporal lobes; it is connected to several subcortical (connections indicated in red) and cortical structures (connections indicated in grey). The major neocortical input to the hippocampus comes from the perirhinal and postrhinal cortices through the entorhinal cortex (EC). The medial entorhinal cortex (MEC) receives a major input from the postrhinal cortex (the rodent homolog of the parahippocampal cortex of primates) which is connected to the visuospatial areas of the parietal lobe; it brings to the hippocampus visuospatial information (VSI) ("where" pathway). On the other hand, the lateral entorhinal cortex (LEC) receives its primary input from perirhinal cortex, which carries object-related information (ORI) ("what" pathway).The visual input from the eyes is conducted through the occipital cortex. The auditory input is conducted through the temporal lobe and the somatosensory system is related to the parietal cortex. This sensory system circuit constitutes the main input of information to the hippocampus, through EC. The subiculum ( $\mathrm{Sb}$ ) is considered the major output region of the hippocampus: it sends projections to other areas of the subicular complex (pre/parasubiculum), to the thalamus, hypothalamus and septum (via fornix), as well as to the deep layers of the EC. On the other hand, CA3 projects mainly to the lateral septum [122] and receives an input mainly from medial septum [232]. Amygdala is related with emotions, playing a role in the memory circuit in associating desire with objects/spatial locations [21]. Amygdala projects to thalamus that in turn projects back to the neocortex, activating the appropriate behavioural output. Brain areas that have been reported to contain place-related neural activity are grey (reviewed by [110]). $E$ encoding, $R$ retrieval, $P L$ place recognition, $R / C$ retrieval/consolidation, VSI visuospatial information ("Where"); ORI object-related information ("What") (b) The hippocampus has the same basic structure in humans, nonhuman primates and rodents. In the tri-synaptic circuit the information flows from layer II in the Entorhinal cortex (EC) made up of the Medial and Lateral Entorhinal Cortex (MEC and LEC) to granule cells in the DG through Perforant Pathway (Lateral Perforant Pathway; LPP and Medial Perforant Pathway; LPP) and then from the granule cells to the CA3 pyramidal cells through the Mossy Fibres (MF), from the CA3 pyramidal cells to the CA1 pyramidal cells through the Schaffer Collaterals (SC) and finally from the CA1 pyramidal cells to the subicular pyramidal cells that in turn project to deep layers of the EC. Additionally, the pyramidal cells of EC send axons directly to CA3 (through the perforant pathway) and to CA1 (through the temporoammonic pathway-TP). The most numerous excitatory input in CA3 arise from the recurrent collaterals (RC). Opyramidal cells-glutamatergic excitatory transmission and GABAergic inhibitory transmission () granular cells-essentially glutamatergic 
encode space as a grid, DG removes this type of encoding to generate a representation of place, producing different representations of distinct places. It is suggested, therefore, that this competition in DG enables individuals to solve spatial pattern separation tasks, being particularly important when the spatial information is very similar, for example, the places are close together. Consistent with this, rats with DG lesions are impaired when performing 'metric spatial pattern separation tasks', which tests the ability to distinguish overlapping spatial patterns [75, 76, 79]. Overall, there is some indication that the DG plays an important role in the encoding of information, helping to build spatial representations for the following CA3 network (Fig. 2b). Additionally, it plays a crucial role in spatial pattern separation in spatial memory tasks.

\section{CA3 region-autoassociative system: encoding versus retrieval}

The CA3 region receives (via Mossy Fibres) an input from the DG, as well as a direct input from the EC, through the Perforant Pathway (Fig. 2b). There is evidence that the DG input into CA3 is essential for encoding new information, but not for retrieval (Rolls 1989; [114]. In contrast, the direct connections to EC through the perforant pathway play an important role in retrieval of information from CA3, especially when an incomplete cue is provided. The CA3 region has been suggested to act as an autoassociation memory. It works effectively as a single network allowing arbitrary associations to be formed between inputs from different parts of the cortex. These associations may involve relating information coming from the visual cortex about the presence of a particular object and information coming from the parietal cortex about its location in the environment [168, 169, 170, 171] (reviewed in [175]). Studies in non-human models suggest that associative learning appears to be impaired by CA3 lesions even when one of the associates is a 'place' [74]; [107]. Associative learning in the CA3 recurrent collateral connections can occur rapidly, enabling the acquisition of a spatial task in as little as one trial $[116,117]$. However, the CA3 region seems to contribute to acquisition of spatial tasks involving multiple trials. CA3 lesioned rats are impaired in acquisition of the standard MWM task, object-place and odourplace paired associate learning, all of which are tasks that require multiple trials to learn $[29,55,74]$.

The mossy fiber input from the DG is important for optimal encoding of information in both fast (one-trial) and continued (over several trials) learning [114, 118], especially when spatial discrimination is difficult (pattern separation needed) [74]. In contrast, the direct perforant path to CA3 is involved in initiating retrieval from the CA3 autoassociation system (Fig. 2b), supporting a pattern completion process when there is an incomplete retrieval cue $[77,118]$. For example, if an association between a place and an object is represented in the hippocampus, the perforant input plays an important role in order to recall the object given the spatial cue, or alternatively to recall the place given an object recall cue (reviewed in [175]). Evidence for this hypothesis comes from studies showing that lesions of the DG or CA3 or Mossy Fiber pathway disrupt the 1-day learning of the Hebb-Williams maze (typical original route maze), but not retrieval of the information if the task had been acquired before the lesion. On the contrary, lesions of the perforant input to the CA3 from the EC disrupt retrieval, but not the learning within a day $[110$, 112].

The CA3 system is reported to be capable of maintaining memories for a short period of time, by maintaining the firing of neurons using excitatory CA3-CA3 connections. In support of this idea, neuron firing has been reported in the CA3 region during the delay period of a short-term spatial memory task in rats [84]. This has also been reported in monkeys in an object-place and locationscene association short-term memory task [228]. Thus, it is predicted that CA3 short-term memory will be very sensitive to interference. For example, if a rat changes location the CA3 representation also moves to represent this change. Therefore, in short-term memory tasks the maintenance of a memory is very dependent on what happens during the delay interval. When there is no task and little distraction in the delay period, the CA3 region may be sufficient to perform the short-memory function alone (reviewed in [175]).

\section{CA1 region-role in memory retrieval}

The CA3 region connects to the CA1 region through the Schaffer Collateral circuit (Fig. 2b) and CA1 outputs are directed towards the subiculum, entorhinal cortex and prefrontal cortex [8]. It has been demonstrated that the CA3-CA1 synapses are associatively modifiable, enabling an efficient retrieval of information from CA3. Interestingly, it has been shown that a considerable loss of information occurs between $\mathrm{CA} 1$ and CA3 if the synapses are non-modifiable $[172,182]$. The CA1 network receives a double set of inputs. Although most of the information comes from CA3, a small proportion (one-sixth) feeds directly through perforant path projections from the entorhinal cortex (mainly layer III of EC) (Fig. 2b) [7, 211]. Several studies have shown that direct inputs from the EC is sufficient for spatial firing in CA1, without the need for further processing via the tri-synaptic circuitry [29]. Furthermore, a recent study showed that direct input from the $\mathrm{EC}$ is necessary for normal spatial firing in the cell population of CA1 and that the firing pattern of place cells in the 
hippocampal area of CA1 are significantly attenuated by selective lesions of layer III of EC [28].

CA1 has often been suggested to act as a "novelty detector", detecting mismatches between cortical information concerning the current situation (through the input from layer III of the entorhinal cortex) with the stored predictions arriving from CA3 (through the Schaffer Collateral pathway) (Fig. 2b). The resulting signal from this "novelty detector" is suggested to be responsible for updating stored information. The isolation of the contributions to CA1 of the direct cortical input and of CA3 (via Schaffer pathway) has revealed different roles in the memory circuitry. Whereas the cortical projection to CA1 is sufficient for place recognition, the Schaffer pathway is necessary for the rapid learning and recall of a spatial location [29, 95, 135]. Studies involving selective lesions in CA1 or CA3 in rat hippocampal areas have shown that CA3 lesions impair the acquisition of a delayed non-match to place task (in eight-arm radial maze) with a 10-s delay, whereas deficits for the CA1 region become apparent when rats are transferred to a 5-min delay [116, 117]. It is suggested that the CA3 system is involved in short delays when acquiring spatial short-term memory, but after acquisition this region is no longer used. At 5 min' delay, the system operates by associative connections between the CA1 region and the EC. This enables acquisition of the spatial information required in the delayed non-match eight-arm radial maze [117].

The CA1 region also appears to be involved in retrieval after longer time delays, with rats lesioned in the CA1 region having no difficulty in encoding new information but impaired in retrieval after a 24-h interval $[100,212]$. Additionally, lesions made in the CA1 region $24 \mathrm{~h}$ post training in a water maze disrupted subsequent recall, whilst CA1 lesions made 3 weeks later did not disrupt retrieval of task [164]. Evidence reviewed elsewhere [175] indicates that the CA1 region makes a special contribution to the temporal aspects of memory, including associations over a delay period, sequence memory and order memory.

\section{Memory consolidation}

Much evidence indicates that the hippocampus has a timelimited role in the consolidation or stabilisation of lasting memory, or both [130, 131, 211]. However, little is known about system and cellular processes mediating consolidation for several hours or longer learning to create lasting memories. Given that the hippocampus is highly connected to the neocortex by back projections, it is generally thought that the neocortex is the final site of long-term storage. In particular, the CA1-subiculum-EC circuit network is thought to be the route by which retrieval to the neocortex occurs (see [127] for a review) (Fig. 2a). Consistent with this idea, damage to the hippocampus in both humans and animals often results in an impairment of recently acquired memories, whilst the recall of memories acquired before the damage occurred remains intact $[59,197]$. Studies in rodents involving reversible inactivation of the hippocampus after training combined with functional imaging data indicate that the hippocampus is important during recall of recently acquired memories, becoming less active during the recall of remote information, while the neocortex gradually builds and adjusts on the basis of much accumulating information $[25,60,129,165,177,211]$. The cortical mechanisms by which memory consolidation and memory retrieval occurs are not clear. Most versions of the consolidation theory agree that both the hippocampus and neocortex act jointly during the initial encoding and storage of a memory, followed by a stage in which the role of the hippocampus is less critical. One of the main difficulties in understanding the mechanisms by which consolidation occurs is the selection of the relevant cortical regions of interest to study [127].

\section{External connections of the hippocampus}

The specific role of hippocampus in learning and memory and the nature of its interactions with other brain structures are critical in order to understand how memories and learning processes support adaptive behaviour. Sensory input comes mainly from the neocortex (visual, audititory and somatosensory information) and is directed to the hippocampus via EC Projections. From the hippocampus they pass via the subiculum and fornix to the thalamus (some fibres pass through the mammillary body in the hypothalamus), that connects back to the neocortex [4] (Fig. 2a). The CA1 network is thought to play an important role in retrieval of information to the neocortex, consequently affecting others parts of the brain involved in guiding behaviour. The CA1-cortical back-projection system is large, in terms of number of synaptic connections, which is likely to be essential for the retrieval of a large number of memories from the hippocampus back to the neocortex. The neocortex provides a way of regulating hippocampal function and consequently influences behaviour. For example, place to object recall should involve back-projections via the CA1 region to the neocortex once objects have become represented within this structure [174]. However, there are other direct sub-cortical outputs of the hippocampus that are also potential routes for retrieval from the hippocampus and may subsequently influence behaviour. For instance, the second sub-cortical pathway that connects the CA1 and subiculum to the mammillary bodies and anterior thalamus is also numerically large, and may potentially provide important information output to regions like the cingulate gyrus (Fig. 2a). The mutual interaction of the cingulate gyrus with neurons in the neocortex enables the completion of the 
memory circuit. The consequence of this is that information eventually returns to the neocortex so subsequent inputs to the hippocampus are affected by its own projections through this memory circuit, providing a potential behavioural output $[175,215]$. In contrast, the direct CA3 output to the medial septum or indirect output via the lateral septum to the medial septum is much less numerous, in terms of number of connections [69, 179]. Given that the medial septum in turn provides cholinergic and GABAergic inputs back to the hippocampus, this route is thought to be more involved in regulating hippocampal function than in a more actiondirected use of information to guide behaviour (reviewed in [175] (Fig. 2a).

\section{An overview}

Looking at the hippocampal circuitry network as whole, we can distinguish essentially a 'Forward Projection System', involving the convergence of information from the EC, to the DG and CA3 and a divergent 'Back Projection System' via the hippocampal CA1 pyramidal cells and subiculum back to the neocortex (Fig. 2a, b). During learning of a new memory, information coming from temporal and parietal lobes, through the EC, reaches the hippocampus through the perforant pathway connections to the DG and CA3 regions. The DG produces a sparse representation of the memory by competitive learning, forcing a new representation on the CA3 region (Mossy Fibres) and supports spatial pattern separation during learning, enabling the necessary spatial discrimination (Encoding). The CA3 associative network plays a critical role in acquisition of spatial rapid one-trial learning and also in (slower) learning across many trials, making possible associations between different parts of the cortex (Encoding).The CA3 is particularly important for short-term memory as it supports pattern completion due to the direct connections to the EC through the Perforant pathway (Retrieval). The modifiable connections from the CA3 neurons to the CA1 neurons allow recoding of information in the CA1. Then the CA1 sets up the associatively learned back-projections to the neocortex that enable subsequent retrieval of information to the neocortex (Consolidation). While, the perforant input to the CA3 is involved in retrieval of short-term memories from the CA3, the perforant input to the CA1 is suggested to be involved in retrieval after longer time intervals (intermediate-term memory) (reviewed in [175]).

Flavonoid intervention and improvements in spatial memory: interactions with the underlying hippocampal circuitry?

There is strong evidence indicating that flavonoids are capable of modulating cellular and molecular processes involved in memory and learning (Table 3) [5, 68, 111, $128,193,217,225]$. However, to date, the precise mechanisms by which they act remain unclear. The consumption of flavonoid-rich foods, such as berries or cocoa, has been shown to limit and even reverse age-dependent deteriorations in the brain's memory architecture. Interestingly, the structural basis for this loss of function has revealed that ageing in the rat brain is associated with circuit-specific loss of connectional integrity rather than the loss of specific neuronal populations [64, 163, 192]. Indeed, studies have indicated that the structural integrity of young and old hippocampus in rats have indicated that the effects of ageing are region- and circuit-specific (reviewed in [31]). Therefore, a possible new perspective into the beneficial effects of flavonoids on memory and learning may concern their actions on particular hippocampal regions and circuits within hippocampus.

One of the most extensively studied flavonoid-rich materials in the context of cognitive performance is Gingko Biloba extract (GBE). GBE has been shown to exert positive effects on learning, concentration and memory $[37,38,44]$ and appears to have a more prominent effect in subjects with cognitive impairments [97, 183, 227]. MWM tasks have been used extensively to examine the cognitive effects of chronic GBE supplementation [183, 218, 219]. The administration of GBE before and during the task acquisition period (3-4 weeks) revealed that GBE at concentrations of 60 and $100 \mathrm{mg} / \mathrm{kg}$ body weight caused a significant improvement in escape latency [218, 219]. Additionally, a 7-week supplementation with GBE caused a more rapid learning of the delay non-match to place task in the RAM [183]. In both cases, the tests imply that GBE improves incremental task learning during the acquisition period. Accordingly, GBE seems to have an effect on acquisition and short-term working memory, but not retrieval of long-term memory of previously acquired tasks [94, 183]. Therefore, it is likely that the observed behavioural effects related to $\mathrm{GBE}$ are dependent on $\mathrm{CA} 3$ region of the hippocampus, as CA3 has been shown to be critical during learning/acquisition of spatial information, but not necessarily involved in long-term recall of previously acquired information in both RAM and MWM tasks [29, $55,116,117,201]$. In support of this, GBE has been shown to markedly improve the performance of both young and aged animals in repeated reversal spatial learning tests (MWM), suggesting that it aids acquisition of rapid learning tasks [94, 219], something which is also dependent on the CA3 recurrent network [141]. As such, future investigations should, therefore, establish whether there is any relationship between the acquisition of task information in GBE supplemented animals and the induction of long-term potentiation (LTP) and its maintenance in CA3 region. 
Table 3 Summary of the studies examining the effect of flavonoid-rich foods (gingko biloba, green teas, blueberry, promegranate juice) and pure flavonoids ((-) epicatechin, Quercetin, Rutin. EGCG, catechin) on neuro-cognitive ability in rodents

\begin{tabular}{|c|c|c|c|}
\hline Feeding Schedule & Maze:Memory Task & Main Findings & Reference \\
\hline \multicolumn{4}{|l|}{ Ginkgo Biloba } \\
\hline $\begin{array}{l}20,30 \text { and } 50 \mathrm{mg} / \mathrm{kg} \text { bw } 1 \mathrm{~h} \\
\text { before the test trial }\end{array}$ & $\begin{array}{l}\text { RAM: reference and working } \\
\text { memory task }\end{array}$ & $\begin{array}{l}\text { Effects of GBE mainly contributable to } \\
\text { cholinergic activity and partly due to a } \\
\text { histaminergic mechanism }\end{array}$ & [231] \\
\hline $\begin{array}{l}10 ; 20 ; 40 \mathrm{mg} / \mathrm{kg} \text { bw of GBE per } \\
\text { day in the interval between } \\
\text { training and testing ( } 17 \text { days) }\end{array}$ & $\begin{array}{l}\text { RAM: olton task and delayed non- } \\
\text { matching to sample; MWM: } \\
\text { classic task and probe trials }\end{array}$ & $\begin{array}{l}\text { No effects in short-term and long term } \\
\text { memory. Possible contribution to } \\
\text { acquisition of the DNMS in RAM }\end{array}$ & {$[183]$} \\
\hline $\begin{array}{l}10 \mathrm{mg} / \mathrm{kg} \text { bw per day for } 28 \text { days } \\
\text { prior to and throughout the } \\
\text { testing }\end{array}$ & $\begin{array}{l}\text { MWM: classic task and probe } \\
\text { trials ( } 5 \text { min and } 2 \text { weeks later), } \\
\text { reversal learning paradigm }\end{array}$ & $\begin{array}{l}\text { No effect on task acquisition or long-term } \\
\text { retention. Effect on ST retention for } \\
\text { animals trained in massed trials. GBE } \\
\text { enhanced reversal learning in massed } \\
\text { and spaced trained animals. }\end{array}$ & [94] \\
\hline $\begin{array}{l}30 \text { and } 60 \mathrm{mg} / \mathrm{kg} \text { bw per day for } \\
30 \text { days (during training and } \\
\text { testing) }\end{array}$ & $\begin{array}{l}\text { MWM: Classic task and reversal } \\
\text { learning paradigm }\end{array}$ & $\begin{array}{l}\text { Egb } 761 \text { enhanced learning in the classic } \\
\text { task in aged rats }(60 \mathrm{mg} / \mathrm{kg}) \text { and in the } \\
\text { repeated reversal task }(30 \text { and } 60 \mathrm{mg} / \\
\mathrm{kg}) \text {. Enhanced LTP in CA1 in } \\
\text { supplemented animals }\end{array}$ & [219] \\
\hline $\begin{array}{l}\text { CL: } 50 \mathrm{mg} / \mathrm{kg} \text { bw } 30 \mathrm{~min} \text { before } \\
\text { testing and after testing. } \\
\text { DNMS: } 100 \text { and } 200 \mathrm{mg} / \mathrm{kg} \\
\text { immediately before the pre-delay } \\
\text { sub-session }\end{array}$ & $\begin{array}{l}\text { RAM: Delayed non-matching to } \\
\text { sample and continuous learning } \\
\text { task }\end{array}$ & $\begin{array}{l}\text { Pre-session administration resulted in } \\
\text { faster continuous maze learning. Dose- } \\
\text { related decrease in errors in delayed } \\
\text { non-match task }\end{array}$ & {$[227]$} \\
\hline $\begin{array}{l}100 \mathrm{mg} / \mathrm{kg} \text { bw per day for } \\
21 \text { days }\end{array}$ & $\begin{array}{l}\text { MWM: classic task and probe trial } \\
(24 \mathrm{~h}) \text {; object recognition test } \\
\text { (non-spatial memory) }\end{array}$ & $\begin{array}{l}\text { Egb } 761 \text { improved spatial and non-spatial } \\
\text { memory in control rats. Preventive } \\
\text { doses of Egb } 761 \text { normalised non- } \\
\text { spatial cognitive deficits and improved } \\
\text { spatial memory in rats chronically } \\
\text { stressed or corticosterone treated }\end{array}$ & [218] \\
\hline \multicolumn{4}{|l|}{ Pomegranate juice } \\
\hline $\begin{array}{l}5 \mathrm{ml} \text { of juice per day for } \\
6 \text { months and a half }\end{array}$ & $\begin{array}{l}\text { MWM: classic task and probe } \\
\text { trials ( } 2 \text { days) }\end{array}$ & $\begin{array}{l}\text { Supplemented mice learned MWM task } \\
\text { faster and had significantly less } \\
\text { accumulation of soluble AB42 and } \\
\text { amyloid deposition in the hippocampus. } \\
\text { Potential effect of PJ in AD should be } \\
\text { considered. }\end{array}$ & {$[87]$} \\
\hline \multicolumn{4}{|l|}{ Green tea } \\
\hline $\begin{array}{l}\text { Green tea catechins }(\mathrm{PE}) \text { mixed } \\
\text { in water at concentrations of } 1 \\
\text { and } 5 \mathrm{~g} / \mathrm{l} \text { for } 26 \text { weeks }\end{array}$ & $\begin{array}{l}\text { RAM: working and reference } \\
\text { memory task }\end{array}$ & $\begin{array}{l}\text { Administration of PE had improved } \\
\text { reference and working memory and } \\
\text { conducted to lower plasma } \\
\text { concentrations of lipid peroxides (LPO) } \\
\text { and greater plasma ferric-reducing anti- } \\
\text { oxidation power. Lower hippocampal } \\
\text { ROS concentrations in treated rats was } \\
\text { also observed. }\end{array}$ & {$[85]$} \\
\hline $\begin{array}{l}\text { Tea polyphenol (TP)- } 0,2 \%(\mathrm{w} / \mathrm{w}) \\
\text { for } 7 \text { weeks }\end{array}$ & $\begin{array}{l}\text { Passive avoidance learning; } \\
\text { Y-maze: continuous alternation } \\
\text { task }\end{array}$ & $\begin{array}{l}\text { Chronic administration of TP improved } \\
\text { cognitive performance and inhibited } \\
\text { acetylcholinesterase (AChE) activity in } \\
\text { scopolamine-induced amnesic mice }\end{array}$ & {$[108]$} \\
\hline \multicolumn{4}{|l|}{ Blueberry } \\
\hline $\begin{array}{l}2 \%(\mathrm{~m} / \mathrm{m}) \text { blueberry incorporated } \\
\text { in the food for } 8 \text { weeks before } \\
\text { testing }\end{array}$ & $\begin{array}{l}\text { MWM:classic task and probe trials } \\
\text { (during acquisition) }\end{array}$ & $\begin{array}{l}\text { Blueberry supplemented rats showed the } \\
\text { greatest increases in GTPase activity, } \\
\text { Ca2+ recovery and dopamina release, } \\
\text { as well as improved spatial memory. }\end{array}$ & {$[102]$} \\
\hline
\end{tabular}


Table 3 continued

\begin{tabular}{|c|c|c|c|}
\hline Feeding Schedule & Maze:Memory Task & Main Findings & Reference \\
\hline $\begin{array}{l}2 \%(\mathrm{~m} / \mathrm{m}) \text { blueberry incorporated } \\
\text { in the food for } 8 \text { weeks before } \\
\text { testing }\end{array}$ & $\begin{array}{l}\text { RAWM: Working and reference } \\
\text { memory task and reversal } \\
\text { learning paradigm }\end{array}$ & $\begin{array}{l}\text { Improvement in LT reference memory } \\
\text { correlated with significant increase in } \\
\text { the levels of IGF-1, IGF-1R and ERK } \\
\text { activation (hippocampal plasticity) }\end{array}$ & [189] \\
\hline $\begin{array}{l}2 \%(\mathrm{~m} / \mathrm{m}) \text { blueberry incorporated } \\
\text { in the food for } 10 \text { weeks before, } \\
\text { during and after testing }\end{array}$ & $\begin{array}{l}\text { MWM: working memory task, } \\
\text { reversal learning paradigm }\end{array}$ & $\begin{array}{l}\text { There was no significant improvement in } \\
\text { spatial memory. Anthocyanins were } \\
\text { found in the cerebellum, cortex and } \\
\text { hippocampus }\end{array}$ & [9] \\
\hline $\begin{array}{l}3,2 \mathrm{mg} / \mathrm{kg} / \mathrm{day} \text { of anthocyanins } \\
\text { administered in blueberry } \\
\text { powder dissolved in water for } \\
4 \text { weeks before training }\end{array}$ & $\begin{array}{l}\text { Inhibitory fear conditioning } \\
\text { learning: Short- and Long-term } \\
\text { memory tasks. RAM: working } \\
\text { and reference memory task }\end{array}$ & $\begin{array}{l}\text { Improvement in ST spatial memory and } \\
\text { ST inhibitory fear conditioning } \\
\text { memory. Positive effect in locomotion }\end{array}$ & [162] \\
\hline $\begin{array}{l}2 \%(\mathrm{~m} / \mathrm{m}) \text { blueberry incorporated } \\
\text { in the food for } 12 \text { weeks during } \\
\text { testing }\end{array}$ & $\begin{array}{l}\text { X maze: Delayed non-matching to } \\
\text { sample }\end{array}$ & $\begin{array}{l}\text { Improvement in spatial working memory } \\
\text { in aged animals (performance } \\
\text { comparable to young animals), } \\
\text { associated with increases in BDNF } \\
\text { synthesis, via ERK/CREB pathway }\end{array}$ & [224] \\
\hline \multicolumn{4}{|l|}{ Epicatechin } \\
\hline $\begin{array}{l}2,5 \mathrm{mg} / \text { day/rat for } 2 \text { weeks } \\
\text { before testing }\end{array}$ & $\begin{array}{l}\text { MWM: Classic task and probe } \\
\text { trials ( } 24 \mathrm{~h}, 1 \text { and } 2 \text { weeks after } \\
\text { acquisition) }\end{array}$ & $\begin{array}{l}\text { Effect of diet on retention after } 24 \mathrm{~h} \text { and } \\
1 \text { week, especially in combination with } \\
\text { exercise. Increased angiogenesis and } \\
\text { neuronal spine density in DG }\end{array}$ & {$[214]$} \\
\hline \multicolumn{4}{|l|}{ Quercetin, Rutin. EGCG, catechin } \\
\hline $\begin{array}{l}\text { EGCG- } 50 \mathrm{mg} / \mathrm{kg} \text {; catechin- } \\
200 \mathrm{mg} / \mathrm{kg}, \text { rutin- } 50 \mathrm{mg} / \mathrm{kg} \text {, } \\
\text { quercetin- } 50 \mathrm{mg} / \mathrm{kg}-30 \mathrm{~min} \\
\text { before the first and second } \\
\text { arterial occlusions }\end{array}$ & RAM: Olton task & $\begin{array}{l}\text { Both rutin and quercetin improved spatial } \\
\text { memory impairment and neuronal death } \\
\text { in the hippocampal CA1 area. }\end{array}$ & [159] \\
\hline
\end{tabular}

$b w$ body weight, $A D$ Alzheimer disease, $R A M$ Radial Arm Maze, $M W M$ Morris Water Maze, $R A W M$ Radial Arm Water Maze

In addition to actions on the CA3 region, EGb 761 $(60 \mathrm{mg} / \mathrm{kg}$ ) has also been observed to significantly increase the magnitude of LTP in the hippocampal CA1 area of aged rats [219]. Interestingly, lesions in CA1 region after $24 \mathrm{~h}$ post-training in the MWM task was shown to disrupt retrieval of the spatial information, whilst lesions made 3 weeks later did not disrupt retrieval of the task [164]. Here, it is likely that the improved information recall in aged animals after $24 \mathrm{~h}$ is related to CA1 region synaptic plasticity as CA1 spatial representations are known to be less stable in aged animals compared to young ones [18, $31,52,208]$. In terms of the underlying pharmacological mechanisms, GBE has been reported to reduce levels of reactive oxygen species (ROS) $[155,156]$, to increase cerebral blood flow [63], to modulate brain fluidity [204], to interact with the muscarinin cholinergic system [36] and to protect the striatal dopaminergic system [161]. Whatever the mechanism, it is likely that GBE bioactives are acting at various levels to enhance the memory system in order that it may transmit information more efficiently through hippocampal circuits. Particularly, it would be valuable to investigate the link between the behavioural outcome in
MWM tasks and the potential action of the diet in plasticity mechanisms in $\mathrm{CA} 1$ and $\mathrm{CA} 3$ regions of the hippocampus.

There is also extensive evidence that berries, in particular blueberries (BB), are effective at reversing age-related deficits in motor function and spatial working memory [9, $19,34,67,81,101,102,115,162,188,189]$. The benefits of anthocyanin-rich blueberries have been shown against both behavioural and neuronal decline associated with ageing [102, 189, 224]. Improvement in spatial working memory in MWM tasks was significantly higher in aged rats (19 months old) supplemented with blueberry (8 weeks supplementation) compared to the group of animals following a normal diet [102]. Much of the research on blueberry supplementation has focused on the potential effects on spatial memory in aged animals. In general, BB appears to have a pronounced effect on short-term memory, demonstrated by improved performance in several memory maze tasks, such as the MWM, eight-arm RAM and an $\mathrm{X}$-maze $[102,162,224]$. Similar to GBE, it is likely that these observed short-term memory improvements are, at least, partially dependent on CA3-CA3 excitatory connections (reviewed in [175]). Interestingly, the effects of ageing in 
CA3 area are rather different from that seen in the CA1 region. Contrary to what is observed in CA1, spatial representations in CA3 seem to be more rigid in aged rats. In young rats, CA3 place maps switch when the animals are moved to a different environment, whilst in the CA3 region, spatial representations in aged rats tend to remain the same even though the surroundings have changed [121, 226]. Accordingly, ageing appears to impair new learning as the existing associations in the CA3-CA3 network tend to dominate cell firing [88]. As such, it seems possible that blueberry intervention may be acting to improve the efficiency of memory by assisting the CA3 network to make the spatial representations in that region more plastic.

Alternatively, blueberry flavonoids may be enhancing efficiency in CA3 indirectly by acting on the DG. DG granule cells are particularly vulnerable to the ageing process $[190,191]$, meaning that if the transfer of information between DG and CA3 declines with age, this will contribute to the failure of aged CA3 networks to build new spatial representations when required (reviewed [31]). This is supported by observations that DG-lesioned rats exhibit a marked difficulty in place strategies, particularly when they are required to deal with one-trial place learning. In addition, animals with lesions in DG show no improvement in reversal learning task in MWM [230]. Interestingly, a significant effect of a BB diet in reversal learning in the Radial Arm Water Maze, a typical one-trial place learning task [189], was reported. Additionally, 8 weeks of blueberry supplementation has been shown to significantly increase the proliferation of precursor cells in the DG of aged rats [189]. The link between DG neurogenesis, cognitive performance and ageing is well documented [47, 80, $104,105,113,143,184,185]$, and may represent one mechanism by which BB flavonoids improve memory by acting on the hippocampus.

Animal studies involving other flavonoid-rich food supplementation such as tea [35] and pomegranate juice [87], or pure flavonols such as quercetin, rutin [159] or fisetin [123] have provided further evidence that dietary flavonoids are beneficial in reversing the course of neuronal and behavioural ageing. For example, the flavanol (-)-epicatechin, especially in combination with exercise, has been observed to enhance the retention, but not the acquisition, of rat spatial memory in water maze tasks [214]. Interestingly, increased angiogenesis and neuronal spine density specifically in the DG of the hippocampus was also observed [214]. However, the same study reports no apparent increase in neuronal proliferation, contrary to what is observed with blueberry [214]. As (-) epicatechin is one of the flavanols present in blueberry, it is worthwhile examining whether the concentrations of (-) epicatechin present in blueberry are likely to have effects on morphology and vasculature in the hippocampus, and if so, where there is a particular target region such as DG. Cross species studies have documented DG as the hippocampal sub-region most sensitive to the effects of ageing [31, 71, 190]; so it is interesting to observe whether blueberry and other flavonoid-rich interventions may affect the DG region selectively [190].

Emerging evidence suggests that flavonoid-rich foods and pure flavonoids are able to affect several different aspects of learning and memory, for example, rapid and slow acquisition, short-term working memory, long-term reference memory, reversal learning and retrieval $[9,81$, $85,87,94,102,103,108,159,162,183,189,214,218$, $219,224,227,231]$. Furthermore, there is already a comprehensive literature regarding how the different regions and circuits in the hippocampus process information and execute functions during the spatial learning in behavioural tasks (MWM, RAM etc.). In addition to this, the ageing effects in the hippocampus are reported to be region specific [31], and so likely to affect different aspects of the memory process. Therefore, investigations into the links between flavonoid intervention and the region-specific changes in the hippocampus observed during ageing are likely to may provide valuable information regarding flavonoid actions. Simultaneous examination of behavioural outcomes and the functioning of the underlying hippocampal circuitry may provide a new insight into how one interprets results from diet-cognition experiments. In general, it is likely that flavonoids are acting at different levels (molecular, cellular, and morphological) to improve the efficiency of the learning process as a whole. However, one may also observe data indicating effects on morphology and vasculature in specific regions of hippocampus as a result of chronic supplementation with flavonoid-rich foods $[189,214]$. Such specific underlying interactions will affect how spatial information is processed in hippocampus and this is highly likely to define outcomes at the behavioural level. Accordingly, a worthwhile future approach to flavonoidcognition studies would be to explore if intervention induces changes in synaptic plasticity within specific hippocampal sub-regions.

How might this be approached? Region- and/or circuitspecific synaptic plasticity can be accessed by measuring alterations in LTP and long-term depression (LTD). Altered neuronal morphology, synaptic connection, cellcell interactions and gene expression contribute to alterations in synaptic plasticity that in turn is reflected in the induction and maintenance of LTP. Such alterations in neuronal morphology can be accessed by examining region-specific changes in spine density and dendritic branching, typically measured in coronal slices of the hippocampus using immunohistochemistry techniques $[40,54,126,160]$. On the other hand, changes in cell-cell 
interactions can be examined by measuring synapse number $[13,16,24,70]$. The induction and persistence of LTP is controlled at the molecular level in neurons, by the activation of several signalling pathways linked to the synthesis and control of a diverse array of neuronal proteins $[6,11,206,207,213,220]$. Flavonoids have been shown to modulate critical neuronal signalling pathways involved in processes of memory, and, therefore, are likely to affect synaptic plasticity and LTP mechanisms (reviewed in [193-195]. In conclusion, investigations into the functional effects of flavonoids on specific regions of the hippocampus will help to clarify their specific mnemonic functions and will help one explain how they influence learning and memory. Any observable alterations in plasticity in the different regions of the hippocampus will reflect upon the network dynamics of neuronal ensembles that ultimately contribute to selective memory and learning outputs.

Acknowledgments The authors are funded by the Biotechnology and Biological Sciences Research Council (BB/F008953/1; BB/ E023185/1; BB/G005702/1).

\section{References}

1. Aggleton JP, Brown MW (1999) Episodic memory, amnesia and the hippocampal-anterior thalamic axis. Behav Brain Sci 22(3): 425-489

2. Aggleton JP, Hunt PR et al (1986) The effects of hippocampal lesions upon spatial and non-spatial tests of working memory. Behav Brain Res 19(2):133-146

3. Aggleton JP, Keith $A B$ et al (1991) Both fornix and anterior thalamic, but not mammillary, lesions disrupt delayed nonmatching-to-position memory in rats. Behav Brain Res 44(2): $151-161$

4. Aggleton JP, Vann SD et al (2000) Identifying cortical inputs to the rat hippocampus that subserve allocentric spatial processes: a simple problem with a complex answer. Hippocampus 10(4): 466-474

5. Agullo G, Gamet-Payrastre L et al (1997) Relationship between flavonoid structure and inhibition of phosphatidylinositol 3-kinase: a comparison with tyrosine kinase and protein kinase C inhibition. Biochem Pharmacol 53(11):1649-1657

6. Alkon DL, Sun MK et al (2007) PKC signaling deficits: a mechanistic hypothesis for the origins of Alzheimer's disease. Trends Pharmacol Sci 28(2):51-60

7. Amaral DG, Ishizuka $\mathrm{N}$ et al (1990) Neurons, numbers and the hippocampal network. Prog Brain Res 83:1-11

8. Amaral DG, Witter MP (1995) The hippocampal formation: the rat nervous system. Academic Press, P. G. San Diego, pp 443-493

9. Andres-Lacueva C, Shukitt-Hale B et al (2005) Anthocyanins in aged blueberry-fed rats are found centrally and may enhance memory. Nutr Neurosci 8(2):111-120

10. Arendash GW, Gordon MN et al (2001) Behavioral assessment of Alzheimer's transgenic mice following long-term Abeta vaccination: task specificity and correlations between Abeta deposition and spatial memory. DNA Cell Biol 20(11): $737-744$
11. Arnsten AF, Ramos BP et al (2005) Protein kinase A as a therapeutic target for memory disorders: rationale and challenges. Trends Mol Med 11(3):121-128

12. Bannerman DM, Yee BK et al (1999) Double dissociation of function within the hippocampus: a comparison of dorsal, ventral and complete hippocampal cytotoxic lesions. Behav Neurosci 113:1170-1188

13. Barnes CA (1979) Memory deficits associated with senescence: a neurophysiological and behavioral study in the rat. J Comp Physiol Psychol 93(1):74-104

14. Barnes CA (1990) Animal models of age-related cognitive decline: handbook of neuropsychology. Elsevier, Amsterdam, pp 169-196

15. Barnes CA, Green EJ et al (1987) Behavioral and neurophysiological examples of functional sparing in senescent rat. Can J Psychol 41:131-140

16. Barnes CA, McNaughton BL (1980) Physiological compensation for loss of afferent synapses in rat hippocampal granule cells during senescence. J Physiol 309:473-485

17. Barnes CA, Nadel L et al (1980) Spatial memory deficit in senescent rats. Can J Psychol 34:29-39

18. Barnes CA, Suster MS et al (1997) Multistability of cognitive maps in the hippocampus of old rats. Nature 388(6639):272-275

19. Barros D, Amaral OB et al (2006) Behavioral and genoprotective effects of vaccinium berries intake in mice. Pharmacol Biochem Behav 84(2):229-234

20. Baxter MG, Gallagher M (1996) Neurobiological substrates of behavioral decline: models and data analytic strategies for individual differences in aging. Neurobiol Aging 17(3):491-495

21. Baxter MG, Parker A et al (2000) Control of response selection by reinforcer value requires interaction of amygdala and orbital prefrontal cortex. J Neurosci 20(11):4311-4319

22. Block F (1999) Global ischemia and behavioural deficits. Prog Neurobiol 58:279-295

23. Blodgett HC, McCutchan K (1947) Place versus response learning in the simple T-maze. J Exp Psychol 37:412-422

24. Bondareff W, Geinisman Y (1976) Loss of synapses in the dentate gyrus of the senescent rat. Am J Anat 145(1):129-136

25. Bontempi B, Laurent-Demir C et al (1999) Time-dependent reorganization of brain circuitry underlying long-term memory storage. Nature 400(6745):671-675

26. Brown MF (1992) Does a cognitive map guide choices in the radial-arm maze? J Exp Psychol Anim Behav Process 18(1): 56-66

27. Brown MF, Rish PA et al (1993) Spatial guidance of choice behavior in the radial-arm maze. J Exp Psychol Anim Behav Process 19(3): 195-214

28. Brun VH, Leutgeb S et al (2008) Impaired spatial representation in CA1 after lesion of direct input from entorhinal cortex. Neuron 57(2):290-302

29. Brun VH, Otnaess MK et al (2002) Place cells and place recognition maintained by direct entorhinal-hippocampal circuitry. Science 296(5576):2243-2246

30. Burgess N, Maguire EA et al (2002) The human hippocampus and spatial and episodic memory. Neuron 35(4):625-641

31. Burke SN, Barnes CA (2006) Neural plasticity in the ageing brain. Nat Rev Neurosci 7(1):30-40

32. Burwell RD (2000) The parahippocampal region: corticocortical connectivity. Parahippocampal Region 911:25-42

33. Burwell RD, Witter MP et al (1995) Perirhinal and postrhinal cortices of the rat: a review of the neuroanatomical literature and comparison with findings from the monkey brain. Hippocampus 5(5):390-408

34. Casadesus G, Shukitt-Hale B et al (2004) Modulation of hippocampal plasticity and cognitive behavior by short-term 
blueberry supplementation in aged rats. Nutr Neurosci 7(5/6): 309-316

35. Chan YC, Hosoda K et al (2006) Favorable effects of tea on reducing the cognitive deficits and brain morphological changes in senescence-accelerated mice. J Nutr Sci Vitaminol (Tokyo) 52(4):266-273

36. Chopin P, Briley M (1992) Effects of four non-cholinergic cognitive enhancers in comparison with tacrine and galanthamine on scopolamine-induced amnesia in rats. Psychopharmacology 106:26-30

37. Clostre F (1999) Gingko Biloba extract (EGb 761): state of knowledgement in the dawn of the year 2000. Ann Pharm Fr 57:1S8-1S88

38. Cohen-Salmon C, Venault P et al (1997) Effects of Ginkgo biloba extract (EGb 761) on learning and possible actions on aging. J Physiol Paris 91(6):291-300

39. Cohen NJ, Eichenbaum H (1993) Memory, amnesia and the hippocampal system. MIT Press, Cambridge

40. Curcio CA, Hinds JW (1983) Stability of synaptic density and spine volume in dentate gyrus of aged rats. Neurobiol Aging 4(1):77-87

41. D'Hooge R, De Deyn PP (2001) Applications of the Morris water maze in the study of learning and memory. Brain Res Brain Res Rev 36(1):60-90

42. Dalm S, Grootendorst J et al (2000) Quantification of swim patterns in the Morris water maze. Behav Res Methods Instrum Comput 32(1):134-139

43. Davachi L, Mitchell JP et al (2003) Multiple routes to memory: distinct medial temporal lobe processes build item and source memories. Proc Natl Acad Sci USA 100(4):2157-2162

44. Diamond BJ, Shiflett SC et al (2000) Ginkgo biloba extract: mechanisms and clinical indications. Arch Phys Med Rehabil 81(5):668-678

45. Diamond DM, Fleshner M et al (1996) Psychological stress impairs spatial working memory: relevance to electrophysiological studies of hippocampal function. Behav Neurosci 110(4):661-672

46. Douglas RJ (1966) Cues for spontaneous alternation. J Comp Physiol Psychol 62(2):171-183

47. Drapeau E, Mayo W et al (2003) Spatial memory performances of aged rats in the water maze predict levels of hippocampal neurogenesis. Proc Natl Acad Sci USA 100(24):14385-14390

48. Dubreuil D, Tixier C et al (2003) Does the radial arm maze necessarily test spatial memory? Neurobiol Learn Mem 79(1):109-117

49. Dudchenko PA (2001) How do animals actually solve the $T$ maze? Behav Neurosci 115(4):850-860

50. Eichenbaum H, Cohen NJ (2001) From conditioning to conscious recollection: memory systems of the brain. Oxford University Press, Oxford

51. Eichenbaum H, Stewart C et al (1990) Hippocampal representation in place learning. J Neurosci 10(11):3531-3542

52. Ekstrom AD, Meltzer J et al (2001) NMDA receptor antagonism blocks experience-dependent expansion of hippocampal "place fields". Neuron 31(4):631-638

53. Evenden JL, Robbins TW (1984) Win-stay behaviour in the rat. Quat J Exp Psychol 36B:1-26

54. Flood DG (1993) Critical issues in the analysis of dendritic extent in aging humans, primates, and rodents. Neurobiol Aging 14(6):649-654

55. Florian C, Roullet P (2004) Hippocampal CA3-region is crucial for acquisition and memory consolidation in Morris water maze task in mice. Behav Brain Res 154(2):365-374

56. Foreman N, Ermakova I (1998) The Radial Arm Maze: twenty years on: handbook of spatial research paradigms and
Methodologies. In: Foreman N, Gillet R (eds) Psychology Press, Sussex 2:87-132

57. Foreman N, Gillet R (eds) (1998) Handbook of spatial research paradigms and methodologies. Psychology Press Ltd, Sussex

58. Frank LM, Stanley GB et al (2004) Hippocampal plasticity across multiple days of exposure to novel environments. J Neurosci 24(35):7681-7689

59. Frankland PW, Bontempi B (2005) The organization of recent and remote memories. Nat Rev Neurosci 6(2):119-130

60. Frankland PW, Bontempi B et al (2004) The involvement of the anterior cingulate cortex in remote contextual fear memory. Science 304(5672):881-883

61. Furuya Y, Yamamoto T et al (1988) A new method for studying working memory by using the three-panel runway apparatus in rats. J Pharmacol 4:183-188

62. Fyhn M, Molden S et al (2004) Spatial representation in the entorhinal cortex. Science 305(5688):1258-1264

63. Gajewski A (1999) Gingko Biloba and memory for a maze. Psychol Rep 84:481-484

64. Gallagher M (2003) Aging and hippocampal/cortical circuits in rodents. Alzheimer Dis Assoc Disord 17(Suppl 2):S45-S47

65. Gallagher M, Burwell R et al (1993) Severity of spatial learning impairments in aging: development of a learning index for performance in the Morris Water Maze. Behav Neurosci 107: 618-636

66. Galli RL (2005) Assessment of animal behavior. Nutritional Neuroscience. C. Prasad. CRC Press, Boca Raton

67. Galli RL, Shukitt-Hale B et al (2002) Fruit polyphenolics and brain aging: nutritional interventions targeting age-related neuronal and behavioral deficits. Ann NY Acad Sci 959:128-132

68. Gamet-Payrastre L, Manenti S et al (1999) Flavonoids and the inhibition of PKC and PI 3-kinase. Gen Pharmacol 32(3):279-286

69. Gaykema RPA, Vanderkuil J et al (1991) Patterns of direct projections from the hippocampus to the medial septum diagonal band complex - anterograde tracing with phaseolus-vulgaris leukoagglutinin combined with immunohistochemistry of choline-acetyltransferase. Neuroscience 43(2/3):349-360

70. Geinisman Y, Bondareff W et al (1977) Partial deafferentation of neurons in the dentate gyrus of the senescent rat. Brain Res 134(3):541-545

71. Geinisman Y, de Toledo-Morrell L et al (1986) Loss of perforated synapses in the dentate gyrus: morphological substrate of memory deficit in aged rats. Proc Natl Acad Sci USA 83(9):3027-3031

72. Geng YQ, Guan JT et al (2007) Behavioral study of calorierestricted rats from early old age. Conf Proc IEEE Eng Med Biol Soc 2007:2393-2395

73. Gerlai R (2001) Behavioral tests of hippocampal function: simple paradigms complex problems. Behav Brain Res 125(1/2): 269-277

74. Gilbert PE, Kesner RP (2003) Localization of function within the dorsal hippocampus: the role of the CA3 subregion in paired-associate learning. Behav Neurosci 117(6):1385-1394

75. Gilbert PE, Kesner RP et al (1998) Memory for spatial location: role of the hippocampus in mediating spatial pattern separation. J Neurosci 18(2):804-810

76. Gilbert PE, Kesner RP et al (2001) Dissociating hippocampal subregions: double dissociation between dentate gyrus and CA1. Hippocampus 11(6):626-636

77. Gold AE, Kesner RP (2005) The role of the CA3 subregion of the dorsal hippocampus in spatial pattern completion in the rat. Hippocampus 15(6):808-814

78. Gonzalez CLR, Kolb B et al (2000) A cautionary note regarding drug and brain lesion studies that use swimming pool tasks: partial reinforcement impairs acquisition of place learning in a 
swimming pool but not on dry land. Behav Brain Res 112(1/2): $43-52$

79. Goodrich-Hunsaker NJ, Hunsaker MR et al (2005) Dissociating the role of the parietal cortex and dorsal hippocampus for spatial information processing. Behav Neurosci 119(5):1307-1315

80. Gould E, Reeves AJ et al (1999) Neurogenesis in the neocortex of adult primates. Science 286(5439):548-552

81. Goyarzu P, Malin DH et al (2004) Blueberry supplemented diet: effects on object recognition memory and nuclear factor-kappa B levels in aged rats. Nutr Neurosci 7(2):75-83

82. Grant SG, O’Dell TJ et al (1992) Impaired long-term potentiation, spatial learning, and hippocampal development in fyn mutant mice. Science 258(5090):1903-1910

83. Hafting T, Fyhn M et al (2005) Microstructure of a spatial map in the entorhinal cortex. Nature 436(7052):801-806

84. Hampson RE, Hedberg T et al (2000) Differential information processing by hippocampal and subicular neurons. Parahippocampal Region 911:151-165

85. Haque AM, Hashimoto M et al (2006) Long-term administration of green tea catechins improves spatial cognition learning ability in rats. J Nutr 136(4):1043-1047

86. Hargreaves EL, Rao G et al (2005) Major dissociation between medial and lateral entorhinal input to dorsal hippocampus. Science 308(5729):1792-1794

87. Hartman RE, Shah A et al (2006) Pomegranate juice decreases amyloid load and improves behavior in a mouse model of Alzheimer's disease. Neurobiol Dis 24(3):506-515

88. Hasselmo ME, Schnell E et al (1995) Dynamics of learning and recall at excitatory recurrent synapses and cholinergic modulation in rat hippocampal region CA3. J Neurosci 15(7 Pt 2):52495262

89. Hodges H (1996) Maze procedures: the radial-arm and water maze compared. Brain Res Cogn Brain Res 3(3/4):167-181

90. Hodges H, Allen Y et al (1991) Effects of cholinergic-rich neural grafts on radial maze performance of rats after excitotoxic lesions of the forebrain cholinergic projection system-I: amelioration of cognitive deficits by transplants into cortex and hippocampus but not into basal forebrain. Neuroscience 45(3) :587-607

91. Hodges H, Green S (1986) Chlordiazepoxide-induced disruption of radial maze exploration in rats. Psychopharmacology 88:460 466

92. Hodges H, Sinden J et al (1993) Foetal CA1 graphs selectively alleviate ischaemic deficits in spatial learning and working memory. J Cereb Blood Flow Metab 13(Suppl 1):S51

93. Hodges H, Sowinski P et al (1995) The selective 5-HT3 receptor antagonist, WAY100289, enhances spatial memory in rats with ibotenate lesions of the forebrain cholinergic projection system. Psychopharmacology (Berl) 117(3):318-332

94. Hoffman JR, Donato A et al (2004) Ginkgo biloba promotes short-term retention of spatial memory in rats. Pharmacol Biochem Behav 77(3):533-539

95. Hollup SA, Kjelstrup KG et al (2001) Impaired recognition of the goal location during spatial navigation in rats with hippocampal lesions. J Neurosci 21(12):4505-4513

96. Holscher C (1999) Stress impairs performance in spatial water maze in learning tasks. Behav Brain Res 100:225-235

97. Itil TM, Eralp E et al (1998) The pharmacological effects of Gingko Biloba, a plant extract, on the brain of dementia patients in comparison with tacrine. Psychopharmacology 34:391-396

98. Jarrard LE (1986) Selective hippocampal lesions and behaviour: implications for current research and theorizing. The Hippocampus. R. L. Iversen and K. H. Pribram. Plenum Press, New York 4:93-126

99. Jarrard LE (1993) On the role of the hippocampus in learning and memory in the rat. Behav Neural Biol 60(1):9-26
100. Jerman T, Kesner RP (2006) Disconnection analysis of CA3 and DG in mediating encoding but not retrieval in a spatial maze learning task. Learn Mem 13:458-464

101. Joseph JA, Denisova NA et al (2003) Blueberry supplementation enhances signaling and prevents behavioral deficits in an Alzheimer disease model. Nutr Neurosci 6(3):153-162

102. Joseph JA, Shukitt-Hale B et al (1999) Reversals of age-related declines in neuronal signal transduction, cognitive, and motor behavioral deficits with blueberry, spinach, or strawberry dietary supplementation. J Neurosci 19(18):8114-8121

103. Joseph JA, Shukitt-Hale B et al (1998) Long-term dietary strawberry, spinach, or vitamin E supplementation retards the onset of age-related neuronal signal-transduction and cognitive behavioral deficits. J Neurosci 18(19):8047-8055

104. Kempermann G, Gage FH (2002) Genetic determinants of adult hippocampal neurogenesis correlate with acquisition, but not probe trial performance, in the water maze task. Eur J Neurosci 16(1):129-136

105. Kempermann G, Kuhn HG et al (1998) Experience-induced neurogenesis in the senescent dentate gyrus. J Neurosci 18(9): 3206-3212

106. Kesner RP, Hopkins RO (2006) Mnemonic functions of the hippocampus: a comparison between animals and humans. Biol Psychol 73(1):3-18

107. Kesner RP, Hunsaker MR et al (2005) The role of CA1 in the acquisition of an object-trace-odor paired associate task. Behav Neurosci 119(3):781-786

108. Kim HK, Kim M et al (2004) Effects of green tea polyphenol on cognitive and acetylcholinesterase activities. Biosci Biotechnol Biochem 68(9):1977-1979

109. King JA, Burgess $\mathrm{N}$ et al (2002) Human hippocampus and viewpoint dependence in spatial memory. Hippocampus 12(6): 811-820

110. Knierim JJ (2006) Neural representations of location outside the hippocampus. Learn Mem 13(4):405-415

111. Kong AN, Yu R et al (2000) Signal transduction events elicited by natural products: role of MAPK and caspase pathways in homeostatic response and induction of apoptosis. Arch Pharm Res 23(1):1-16

112. Kritz-Silverstein D, Von Muhlen D et al (2003) Isoflavones and cognitive function in older women: the SOy and postmenopausal health in aging (SOPHIA) study. Menopause 10(3):196-202

113. Kuhn HG, Dickinson-Anson H et al (1996) Neurogenesis in the dentate gyrus of the adult rat: age-related decrease of neuronal progenitor proliferation. J Neurosci 16(6):2027-2033

114. Lassalle JM, Bataille T et al (2000) Reversible inactivation of the hippocampal mossy fiber synapses in mice impairs spatial learning, but neither consolidation nor memory retrieval, in the Morris navigation task. Neurobiol Learn Mem 73(3): 243-257

115. Lau FC, Shukitt-Hale B et al (2006) Beneficial effects of berry fruit polyphenols on neuronal and behavioral aging. J Sci Food Agricult 86(14):2251-2255

116. Lee I, Kesner RP (2002) Differential contribution of NMDA receptors in hippocampal subregions to spatial working memory. Nat Neurosci 5(2):162-168

117. Lee I, Kesner RP (2003) Differential roles of dorsal hippocampal subregions in spatial working memory with short versus intermediate delay. Behav Neurosci 117(5):1044-1053

118. Lee I, Kesner RP (2004) Encoding versus retrieval of spatial memory: double dissociation between the dentate gyrus and the perforant path inputs into $\mathrm{CA} 3$ in the dorsal hippocampus. Hippocampus 14(1):66-76

119. Lee YB, Lee HJ et al (2005) Soy isoflavones and cognitive function. J Nutr Biochem 16(11):641-649 
120. Letenneur L, Proust-Lima $C$ et al (2007) Flavonoid intake and cognitive decline over a 10-year period. Am J Epidemiol 165(12):1364-1371

121. Leutgeb S, Leutgeb JK et al (2004) Distinct ensemble codes in hippocampal areas CA3 and CA1. Science 305(5688): 1295-1298

122. Leutgeb S, Mizumori SJ (2002) Context-specific spatial representations by lateral septal cells. Neuroscience 112(3):655-663

123. Maher P, Akaishi T et al (2006) Flavonoid fisetin promotes ERK-dependent long-term potentiation and enhances memory. Proc Natl Acad Sci USA 103(44):16568-16573

124. Malkova L, Bachevalier J et al (2001) Neurotoxic lesions of perirhinal cortex impair visual recognition memory in rhesus monkeys. NeuroReport 12(9):1913-1917

125. Mandel S, Youdim MB (2004) Catechin polyphenols: neurodegeneration and neuroprotection in neurodegenerative diseases. Free Radic Biol Med 37(3):304-317

126. Markham JA, McKian KP et al (2005) Sexually dimorphic aging of dendritic morphology in CA1 of hippocampus. Hippocampus 15(1):97-103

127. Martin SJ, Clark RE (2007) The rodent hippocampus and spatial memory: from synapses to systems. Cell Mol Life Sci 64(4): 401-431

128. Matter WF, Brown RF et al (1992) The inhibition of phosphatidylinositol 3-kinase by quercetin and analogs. Biochem Biophys Res Commun 186(2):624-631

129. Maviel T (2004) Sites of neocortical reorganization critical for remote spatial memory (vol 305, pg 96, 2004). Science 305(5686):946

130. McGaugh JL (1999) The perseveration-consolidation hypothesis: Mueller and Pilzecker, 1900. Brain Res Bull 50(5/6):445-446

131. McGaugh JL (2000) Memory-a century of consolidation. Science 287(5451):248-251

132. Mcnaughton BL, Barnes CA et al (1983) The contributions of position, direction, and velocity to single unit-activity in the hippocampus of freely-moving rats. Exp Brain Res 52(1):41-49

133. Miyashita Y, Kameyama M et al (1998) Consolidation of visual associative long-term memory in the temporal cortex of primates. Neurobiol Learn Mem 70(1/2):197-211

134. Miyashita Y, Okuno $\mathrm{H}$ et al (1996) Feedback signal from medial temporal lobe mediates visual associative mnemonic codes of inferotemporal neurons. Brain Res Cogn Brain Res 5(1/2):81-86

135. Mizumori SJY, Barnes CA et al (1989) Reversible inactivation of the medial septum-selective effects on the spontaneous unit-activity of different hippocampal cell-types. Brain Res 500(1/2):99-106

136. Morris R (1984) Developments of a water-maze procedure for studying spatial learning in the rat. J Neurosci Methods 11(1):47-60

137. Morris RGM (1981) Spatial localization does not require the presence of local cues. Learn Motiv 12:239-261

138. Nadel L, Moscovitch M (1997) Memory consolidation, retrograde amnesia and the hippocampal complex. Curr Opin Neurobiol 7(2):217-227

139. Nakamura EM, da Silva EA et al (1991) Reversible effects of acute and long-term administration of delta-9-tetrahydrocannabinol (THC) on memory in the rat. Drug Alcohol Depend 28(2):167-175

140. Nakazawa K, Quirk MC et al (2002) Requirement for hippocampal CA3 NMDA receptors in associative memory recall. Science 297(5579):211-218

141. Nakazawa K, Sun LD et al (2003) Hippocampal CA3 NMDA receptors are crucial for memory acquisition of one-time experience. Neuron 38(2):305-315

142. Nelson A, Lebessi A et al (1997) Comparison of effects of global cerebral ischaemia on spatial learning in the standard and radial water maze: relationship of hippocampal damage to performance. Behav Brain Res 85(1):93-115

143. Nilsson M, Perfilieva E et al (1999) Enriched environment increases neurogenesis in the adult rat dentate gyrus and improves spatial memory. J Neurobiol 39(4):569-578

144. Norman G, Eacott MJ (2005) Dissociable effects of lesions to the perirhinal cortex and the postrhinal cortex on memory for context and objects in rats. Behav Neurosci 119(2):557-566

145. Norman KA, O’Reilly RC (2003) Modeling hippocampal and neocortical contributions to recognition memory: a complementarylearning-systems approach. Psychol Rev 110(4):611-646

146. Nunn JA, Le Peillet E et al (1991) CA1 cell loss produces deficits in the water maze but not in the radial maze. Soc Neurosci Abstr 17:108

147. Nunn JA, LePeillet E et al (1994) Global ischaemia: hippocampal pathology and spatial deficits in the water maze. Behav Brain Res 62(1):41-54

148. O'Keefe J (1984) Spatial memory within and without the hippocampal system: neurobiology of the Hippocampus. W. Seifert. Academic Press, London, pp 375-403

149. O'Keefe J (2007) The hippocampus book. Oxford University Press, New York

150. O'Keefe J, Conway DH (1980) On the trail of the hippocampal engram. Physiol Psychol 8:229-238

151. O'Keefe J, Nadel L (1978) The hippocampus as a cognitive map. Clarendon Press, Oxford

152. Olton DS, Becker JT et al (1980) Hippocampal function: working memory or cognitive mapping? Physiol Psychol 8: 239-246

153. Olton DS, Collinson C (1979) Intramaze cues and odor trails fail to direct choice behaviour on an elevated maze. Ann Learn Behav 7:221-223

154. Olton DS, Samuelson RJ (1976) Remembrance of places pastspatial memory in rats. J Exp Psychol Anim Behav Process 2:97-116

155. Oyama Y, Chikahisa L et al (1996) Ginkgo biloba extract protects brain neurons against oxidative stress induced by hydrogen peroxide. Brain Res 712(2):349-352

156. Oyama Y, Fuchs PA et al (1994) Myricetin and quercetin, the flavonoid constituents of Ginkgo biloba extract, greatly reduce oxidative metabolism in both resting and $\mathrm{Ca}(2+)$-loaded brain neurons. Brain Res 635(1/2):125-129

157. Poucet B (1993) Spatial cognitive maps in animals: new hypotheses on their structure and neural mechanisms. Psychol Rev 100(2):163-182

158. Poucet B, Benhamou S (1997) The neuropsychology of spatial cognition in the rat. Crit Rev Neurobiol 11(2/3):101-120

159. Pu F, Mishima K et al (2007) Neuroprotective effects of quercetin and rutin on spatial memory impairment in an 8-arm radial maze task and neuronal death induced by repeated cerebral ischemia in rats. J Pharmacol Sci 104(4):329-334

160. Pyapali GK, Turner DA (1996) Increased dendritic extent in hippocampal CA1 neurons from aged F344 rats. Neurobiol Aging 17(4):601-611

161. Ramassamy C, Clostre F et al (1990) Prevention by a Ginkgo Biloba extract (GBE 761) of the dopaminergic neurotoxicity of MPTP. J Pharm Pharmacol 42:785-789

162. Ramirez MR, Izquierdo I et al (2005) Effect of lyophilised vaccinium berries on memory, anxiety and locomotion in adult rats. Pharmacol Res 52(6):457-462

163. Rapp PR, Stack EC et al (1999) Morphometric studies of the aged hippocampus: I. Volumetric analysis in behaviorally characterized rats. J Comp Neurol 403(4):459-470

164. Remondes M, Schuman EM (2004) Role for a cortical input to hippocampal area CA1 in the consolidation of a long-term memory. Nature 431(7009):699-703 
165. Riedel G, Micheau J et al (1999) Reversible neural inactivation reveals hippocampal participation in several memory processes. Nat Neurosci 2(10):898-905

166. Roberge MC, Messier C et al (2008) Food restriction induces long-lasting recovery of spatial memory deficits following global ischemia in delayed matching and non-matching-to-sample radial arm maze tasks. Neuroscience 156(1):11-29

167. Rodefer JS, Baxter MG (2007) Neuropsychology of cognitive aging in rodents. Brain Aging: Models, Methods and Mechanisms. D. R. Riddle, CRC Press, Boca Raton

168. Rolls ET (1989) Functions of neuronal networks in the hippocampus and cerebral cortex in memory: models of brain function. R. M. J. Cotterill. Cambridge University Press, Cambridge, pp 15-33

169. Rolls ET (1989) The representation and storage of information in neuronal networks in the primate cerebral cortex and hippocampus: the Computing Neuron. R. Durbin, C. Miall and G. Mitchison. Addison-Wesley, Wokingham, pp 125-159

170. Rolls ET (1990) Functions of the primate hippocampus in spatial processing and memory: neurobiology of comparative cognition. D. S. Olton and R. P. Kesner. L. Erlbaum, New Jersey, pp 339-362

171. Rolls ET (1991) Functions of the primate hippocampus in spatial and nonspatial memory. Hippocampus 1(3):258-261

172. Rolls ET (1995) A model of the operation of the hippocampus and entorhinal cortex in memory. Int J Neural Syst 6:51-70

173. Rolls ET (1996) A theory of hippocampal function in memory. Hippocampus 6(6):601-620

174. Rolls ET, Deco G (2002) Computational neuroscience of vision. Oxford University Press, Oxford

175. Rolls ET, Kesner RP (2006) A computational theory of hippocampal function, and empirical tests of the theory. Prog Neurobiol 79(1):1-48

176. Rolls ET, Xiang JZ (2006) Spatial view cells in the primate hippocampus and memory recall. Rev Neurosci 17(1/2): 175-200

177. Ross RS, Eichenbaum H (2006) Dynamics of hippocampal and cortical activation during consolidation of a nonspatial memory. J Neurosci 26(18):4852-4859

178. Sandi C (1998) The role and mechanisms of action of glucocorticoid involvement in memory storage. Neural Plast 6:41-52

179. Saper CB, Swanson LW et al (1979) Some efferent connections of the rostral hypothalamus in the squirrel-monkey (SaimiriSciureus) and cat. J Comp Neurol 184(2):205-241

180. Sarter M (2004) Animal cognition: defining the issues. Neurosci Biobehav Rev 28(7):645-650

181. Schenk F (1998) The Morris Water Maze: handbook of spatial research paradigms and methodologies. In: Foreman N, Raphael G (eds) Psychology Press, Sussex, 2:145-181

182. Schultz SR, Rolls ET (1999) Analysis of information transmission in the Schaffer collaterals. Hippocampus 9(5):582-598

183. Shif O, Gillette K et al (2006) Effects of Ginkgo biloba administered after spatial learning on water maze and radial arm maze performance in young adult rats. Pharmacol Biochem Behav 84(1):17-25

184. Shors TJ, Miesegaes G et al (2001) Neurogenesis in the adult is involved in the formation of trace memories. Nature 410(6826): 372-376

185. Shors TJ, Townsend DA et al (2002) Neurogenesis may relate to some but not all types of hippocampal-dependent learning. Hippocampus 12(5):578-584

186. Shrager Y, Bayley PJ et al (2007) Spatial memory and the human hippocampus. Proc Natl Acad Sci USA 104(8): 2961-2966

187. Shu SY, Wu YM et al (2003) Interactions among memoryrelated centers in the brain. J Neurosci Res 71(5):609-616
188. Shukitt-Hale B, Lau FC et al (2008) Berry fruit supplementation and the aging brain. J Agric Food Chem 56:636-641

189. Shukitt-Hale B, McEwen JJ et al (2004) Effect of age on the radial arm water maze - a test of spatial learning and memory. Neurobiol Aging 25(2):223-229

190. Small SA, Chawla MK et al (2004) Imaging correlates of brain function in monkeys and rats isolates a hippocampal subregion differentially vulnerable to aging. Proc Natl Acad Sci USA 101(18):7181-7186

191. Small SA, Tsai WY et al (2002) Imaging hippocampal function across the human life span: is memory decline normal or not? Ann Neurol 51(3):290-295

192. Smith TD, Adams MM et al (2000) Circuit-specific alterations in hippocampal synaptophysin immunoreactivity predict spatial learning impairment in aged rats. J Neurosci 20(17):6587-6593

193. Spencer JP (2007) The interactions of flavonoids within neuronal signalling pathways. Genes Nutr 2(3):257-273

194. Spencer JP (2008) Flavonoids: modulators of brain function? Br J Nutr 99E(Suppl 1):ES60-ES77

195. Spencer JP (2008) Food for thought: the role of dietary flavonoids in enhancing human memory, learning and neuro-cognitive performance. Proc Nutr Soc 67(2):238-252

196. Squire LR (1986) Mechanisms of memory. Science 232(4758): $1612-1619$

197. Squire LR, Clark RE et al (2001) Retrograde amnesia. Hippocampus 11(1):50-55

198. Squire LR, Kandel ER (2009) From mind to molecules. Ben Roberts, Singapore

199. Squire LR, Stark CEL et al (2004) The medial temporal lobe. Annu Rev Neurosci 27:279-306

200. Squire LR, Zola SM (1996) Structure and function of declarative and nondeclarative memory systems. Proc Natl Acad Sci USA 93(24): 13515-13522

201. Steele RJ, Morris RG (1999) Delay-dependent impairment of a matching-to-place task with chronic and intrahippocampal infusion of the NMDA-antagonist D-AP5. Hippocampus 9(2): 118-136

202. Stewart CA, Morris RGM (1993) The watermaze. behavioural neuroscience: a practical approach. In: Sahgal A (ed) IRL Press, Oxford, 1:107-122

203. Stolberg A (2005) Ranking of memories and behavioral strategies in the radial maze. Acta Neurobiol Exp 65(1):39-49

204. Stoll S, Scheuer K et al (1996) Ginkgo biloba extract (EGb 761) independently improves changes in passive avoidance learning and brain membrane fluidity in the aging mouse. Pharmacopsychiatry 29(4):144-149

205. Suzuki WA, Miller EK et al (1997) Object and place memory in the macaque entorhinal cortex. J Neurophysiol 78(2):1062-1081

206. Sweatt JD (2001) The neuronal MAP kinase cascade: a biochemical signal integration system subserving synaptic plasticity and memory. J Neurochem 76(1):1-10

207. Sweatt JD (2004) Mitogen-activated protein kinases in synaptic plasticity and memory. Curr Opin Neurobiol 14(3):311-317

208. Thompson LT, Best PJ (1990) Long-term stability of the place-field activity of single units recorded from the dorsal hippocampus of freely behaving rats. Brain Res 509(2):299308

209. Thorpe CM, Jacova $C$ et al (2004) Some pitfalls in measuring memory in animals. Neurosci Biobehav Rev 28(7):711-718

210. Tolman EC, Gleitman H (1949) Studies in spatial learning; place and response learning under different degrees of motivation. J Exp Psychol 39(5):653-659

211. Treves A, Rolls ET (1994) Computational analysis of the role of the hippocampus in memory. Hippocampus 4(3):374-391

212. Vago DR, Kesner RP (2005) An electrophysiological and behavioural characterization of the temporoammonic pathway: 
disruption produces deficits in retrieval and spatial mismatch. Society for Neuroscience Abstracts

213. van der Heide LP, Ramakers GM et al (2006) Insulin signaling in the central nervous system: learning to survive. Prog Neurobiol 79(4):205-221

214. van Praag H, Lucero MJ et al (2007) Plant-derived flavanol (-)epicatechin enhances angiogenesis and retention of spatial memory in mice. J Neurosci 27(22):5869-5878

215. Vann SD, Aggleton JP (2004) The mammillary bodies: two memory systems in one? Nat Rev Neurosci 5(1):35-44

216. Vauzour D, Vafeiadou K et al (2008) The neuroprotective potential of flavonoids: a multiplicity of effects. Genes Nutr 3(3/4): $115-126$

217. Vlahos CJ, Matter WF et al (1994) A specific inhibitor of phosphatidylinositol 3-kinase, 2-(4-morpholinyl)-8-phenyl-4H-1benzopyran-4-one (LY294002). J Biol Chem 269(7):5241-5248

218. Walesiuk A, Trofimiuk E et al (2006) Ginkgo biloba normalizes stress- and corticosterone-induced impairment of recall in rats. Pharmacol Res 53(2): 123-128

219. Wang Y, Wang L et al (2006) The in vivo synaptic plasticity mechanism of EGb 761-induced enhancement of spatial learning and memory in aged rats. Br J Pharmacol 148(2):147-153

220. Wei F, Qiu C et al (2002) Calcium calmodulin-dependent protein kinase IV is required for fear memory. Nat Neurosci 5:573-579

221. Wenk GL (1998) Current protocols in neuroscience. Retrieved 10 July 2009

222. Wenk GL (2004) Assessment of spatial memory using the radial arm maze and Morris water maze. Curr Protoc Neurosci Chapter 8: Unit 85A

223. Whishaw IQ (1989) Dissociating performance and learningdeficits on spatial navigation tasks in rats subjected to cholinergic muscarinic blockade. Brain Res Bull 23(4/5):347-358

224. Williams CM, El Mohsen MA et al (2008) Blueberry-induced changes in spatial working memory correlate with changes in hippocampal CREB phosphorylation and brain-derived neurotrophic factor (BDNF) levels. Free Radic Biol Med 45(3):295-305
225. Williams RJ, Spencer JP et al (2004) Flavonoids: antioxidants or signalling molecules? Free Radic Biol Med 36(7):838-849

226. Wilson IA, Ikonen S et al (2005) Age-associated alterations of hippocampal place cells are subregion specific. J Neurosci 25(29):6877-6886

277. Winter JC (1998) The effects of an extract of Ginkgo biloba, EGb 761, on cognitive behavior and longevity in the rat. Physiol Behav 63(3):425-433

228. Wirth S, Yanike M et al (2003) Single neurons in the monkey hippocampus and learning of new associations. Science 300(5625):1578-1581

229. Witter MP, Wouterlood FG et al (2000) Anatomical organization of the parahippocampal-hippocampal network. Parahippocampal Reg 911:1-24

230. Xavier GF, Oliveira-Filho FJ et al (1999) Dentate gyrus-selective colchicine lesion and disruption of performance in spatial tasks: difficulties in "place strategy" because of a lack of flexibility in the use of environmental cues? Hippocampus 9(6): 668-681

231. Yamamoto Y, Adachi Y et al (2007) Ginkgo biloba extract improves spatial memory in rats mainly but not exclusively via a histaminergic mechanism. Brain Res 1129(1):161-165

232. Zhou TL, Tamura R et al (1999) Comparison of medial and lateral septal neuron activity during performance of spatial tasks in rats. Hippocampus 9(3):220-234

233. Zola-Morgan S, Squire LR et al (1989) Lesions of the amygdala that spare adjacent cortical regions do not impair memory or exacerbate the impairment following lesions of the hippocampal formation. J Neurosci 9(6):1922-1936

234. Zola-Morgan S, Squire LR et al (1989) Lesions of perirhinal and parahippocampal cortex that spare the amygdala and hippocampal formation produce severe memory impairment. J Neurosci 9(12):4355-4370

235. Zola-Morgan S, Squire LR et al (1994) Severity of memory impairment in monkeys as a function of locus and extent of damage within the medial temporal lobe memory system. Hippocampus 4(4):483-495 